J. Lake Sci.(湖泊科学), 2021, 33(2): 632-646

DOI 10. 18307/2021. 0227

(c) 2021 by Journal of Lake Sciences

\title{
大柴旦盐湖中镭同位素分布特征来源及示踪意义
}

\author{
孔凡翠 ${ }^{1,2 * *}$, 杨英鬼头 ${ }^{3}$, 马玉军 ${ }^{4}$, 沙占江 $^{4,5}$, 凌智永 ${ }^{1,2}$, 王建萍 ${ }^{1,2}$ \\ (1:中国科学院青海盐湖研究所,中国科学院盐湖资源综合高效利用重点实验室,西宁 810008) \\ (2: 青海省盐湖地质与环境重点实验室,西宁 810008) \\ (3: 青海大学,西宁 810016) \\ ( 4 : 青海师范大学地理科学学院, 青海省自然地理与环境过程重点实验室, 青藏高原地表过程与生态保育教育部重点实 \\ 验室, 西宁 810008) \\ (5:高原科学与可持续发展研究院,西宁 810016)
}

\begin{abstract}
摘 要: 为了查明大柴旦湖周围水体相互作用过程,2016 年 3 月和 7 月分别采集了大柴旦周围多种水体样品、悬浮颗粒 物和湖底沉积物. 测试了大柴旦盐湖、深部地下热水、表层地下水热水、浅层地下水、河流水体中镭同位素的活度值, 通过 解吸和扩散实验, 获得了河流悬浮颗粒物和湖底沉积物扩散的镭同位素活度值. 结果表明: 河口区 (3L10、3L11、3L12) ${ }^{223} \mathrm{Ra} 、{ }^{224} \mathrm{Ra} 、{ }^{226} \mathrm{Ra}$ 和 ${ }^{228} \mathrm{Ra}$ 活度比湖中心的活度值高, 湖水中 ${ }^{223} \mathrm{Ra} 、{ }^{224} \mathrm{Ra} 、{ }^{226} \mathrm{Ra}$ 和 ${ }^{228} \mathrm{Ra}$ 活度先随着盐度的增加而升高, 当 盐度大于 $168.99 \%$ 时, 则随着盐度的增加而降低, 这表明镭同位素在进入湖体是先发生解吸, 后发生镭同位素的共沉淀. 深部地下热水 ${ }^{223} \mathrm{Ra} 、{ }^{224} \mathrm{Ra}$ 和 ${ }^{228} \mathrm{Ra}$ 的活度值是表层地下热水 ${ }^{223} \mathrm{Ra} 、{ }^{224} \mathrm{Ra}$ 和 ${ }^{228} \mathrm{Ra}$ 活度值的 $3 \sim 4$ 倍, 而 ${ }^{226} \mathrm{Ra}$ 活度值正好相 反, 表层地下热水中 ${ }^{226} \mathrm{Ra}$ 的活度值比深部地下热水中 ${ }^{226} \mathrm{Ra}$ 的活度值高, 在表层具有明显的积累现象. 这是由于短半衰 ${ }^{{ }_{H}{ }^{223}} \mathrm{Ra} 、{ }^{224} \mathrm{Ra}$ 和 ${ }^{228} \mathrm{Ra}$ 发生衰减, 而长半衰期 ${ }^{226} \mathrm{Ra}$ 得到积累的原因, 从而表明镭同位素的运移方向是从深部往上涌的过 程. 大柴旦盐湖中的镭同位素主要来源于深部地下热水、浅层地下水和河流. 大柴旦周围水循环过程是雨和冰雪融水下 渗补给深部和浅层地下水以及地表径流; 深部地下热水一部分上涌至表层, 经过出山口之后全部转化为浅层地下水,一 部分通过深大断裂汇集到大柴旦湖; 浅层地下水直接汇集到湖盆; 地表径流在山区下渗补给浅层地下水,丰水期汇人到 湖盆.
\end{abstract}

关键词: 镭同位素; 镭同位素来源; 水循环; 大柴旦盐湖

\section{The distribution and sources of radium isotopes in Da Qaidam salt lake*}

Kong Fancui $^{1,2 * *}$, Yang Yingkui ${ }^{3}$, Ma Yujun ${ }^{4}$, Sha Zhanjiang ${ }^{4,5}$, Ling Zhiyong ${ }^{1,2}$ \& Wang Jianping ${ }^{1,2}$

(1: Key Laboratory of Comprehensive and Highly Efficient Utilization of Salt Lake Resources, Qinghai Institute of Salt Lakes, Chinese Academy of Sciences, Xining 810008, P.R. China)

(2: Qinghai Provincial Key Laboratory of Geology and Environment of Salt Lakes, Xining 810008, P.R.China)

(3: Qinghai University, Xining 810016, P.R.China)

(4: College of Geographical Sciences, Qinghai Normal University, Key Laboratory of Natural Geography and Environmental Process in Qinghai Province Education, Qinghai Normal University, Key Laboratory of Tibetan Plateau Land Surface Processes and Ecological Conservation, Ministry of Education, Xining 810008, P.R.China)

(5: Academy of Plateau Science and Sustainability, Xining 810016, P.R.China)

Abstract: In order to understand hydrologic cycle around Da Qaidam salt lake, water and suspended particulate matter (SPM) and sediments samples were collected in March and July in 2016. The activities of radium isotopes of brine water, deep hot spring wa-

* 2020-03-06 收稿; 2020-04-28 收修改稿.

中国科学院青年创新促进会项目(2018468)、国家自然科学基金项目(41702268)、青海科技厅项目(2020-ZJ-974Q, 2021-ZJ-755)、中国科学院重点部署项目 (ZDRW-ZS-2020-3) 和第二次青藏高原综合科学考察项目 (2019QZKK0805) 联合资助.

** 通信作者; E-mail: kfc@isl.ac.cn. 
ter, shallow spring water and river water were measurement. Moreover, the radium isotopes activities from SPM and sediment were obtained by experiments of desorption and diffusion. The results showed that the activities of ${ }^{223} \mathrm{Ra},{ }^{224} \mathrm{Ra},{ }^{226} \mathrm{Ra}$ and ${ }^{228} \mathrm{Ra}$ of lake water in estuary were higher than those of in lake centre, and they increase with the salinity, and then decrease with the salinity when salinity is greater than $168.99 \%$, suggesting that radium were desorbed when groundwater or river water met salt lake water at beginning at low salinity, and radium were co-precipitation with $\mathrm{Ca}$ or $\mathrm{Ba}$ at high salinity. The activity value of ${ }^{223} \mathrm{Ra},{ }^{224} \mathrm{Ra}$ and ${ }^{228} \mathrm{Ra}$ in deep hot spring water are about 3-4 times as much as those in shallow hot spring water. However, ${ }^{226}$ Ra activity values in shallow hot spring water are higher than that of deep hot spring water, which show an obvious accumulation phenomenon at the surface. This is because half-life of ${ }^{223} \mathrm{Ra},{ }^{224} \mathrm{Ra}$ and ${ }^{228} \mathrm{Ra}$ is very short, it is easy to attenuate, while the long half-life ${ }^{226} \mathrm{Ra}$ easy to accumulate, indicating that the migration direction of Radium is from deep to upwelling. The sources of radium in Da Qaidam salt lake are mainly from deep hot spring water, shallow groundwater and river water. The infiltration of rain and melt snow water to recharge deep and shallow groundwater and surface runoff. A part of the deep hot water rises to the surface, and then converted into shallow groundwater after passing through the mountain pass. The other part of deep hot water were flowed into Da Qaidam salt lake by the deep fault. The shallow groundwater entering into the lake basin. Surface runoff supply shallow groundwater by infiltration at and inflow into the lake basin during wet season.

Keywords: Radium isotopes; the source of radium; hydrologic cycle; Da Qaidam salt lake

大柴旦湖周围地表水和地下水输送的物质是湖中资源的重要物质来源, 尤其是通过地下水 (特别是湖 北面的温泉水中嗍浓度高达 $40.68 \mathrm{mg} / \mathrm{L})$ 的排放向盐湖输送的物资通量 ${ }^{[1]}$. 地下水输送对盐湖补给起着非 常重要的作用,但由于地下水埋藏地下往往被忽视而又不易检测. 从补给来源看, 大柴旦盐湖的水体到底是 单一深部热水补给还是各种水源水补给? 从补给模式看, 是热水通过地下潜流补给还是地下热水通过断裂 带渗流与冷泉水、大气降水共同补给还不清楚, 地下水的输人提供了盐湖最初的物源, 对盐湖资源的形成、 演化及成盐成矿有着重要的作用.

自然界中天然存在 4 种镭同位素, 分别是 ${ }^{226} \mathrm{Ra}\left(T_{1 / 2}=1600 \mathrm{a}\right) 、{ }^{228} \mathrm{Ra}\left(T_{1 / 2}=5.75 \mathrm{a}\right) 、{ }^{224} \mathrm{Ra}\left(T_{1 / 2}=3.66 \mathrm{~d}\right)$ 和 ${ }^{223} \mathrm{Ra}\left(T_{1 / 2}=11.4 \mathrm{~d}\right)$, 虽然它们的物理、化学性质相同, 但它们的核性质却具有较大差异, 它们半衰期不同, 而且来源也不相同, 因而在水环境中呈现不同的地球化学行为 ${ }^{[2]}$, 不同的半衰期使得它们广泛应用于水体 混合和水体滞留间 ${ }^{[3-4]}$ 、地下水排放通量 ${ }^{[5-7]}$ 、间隙水/上覆水交换速率 ${ }^{[8]}$ 等方面. Moore 以 $^{223} \mathrm{Ra}$ 为分母对 ${ }^{224} \mathrm{Ra}$ 进行标准化,消除水团混合不均匀等因素造成的影响,计算了美国东海岸 South Atlantic Bight 离岸 50 $\mathrm{km}$ 以内海域的水体扩散速率为 $360 \sim 420 \mathrm{~m}^{2} / \mathrm{s}^{[9]}$, 美国墨西哥湾东北部 Apalachee Bay 的水体扩散速率为 $2.7 \sim 12 \mathrm{~m}^{2} / \mathrm{s}^{[10]}$. Krest 等根据墨西哥湾内的密西西比河和阿查法拉亚河河口混合区的长半衰期镭同位素 ${ }^{226} \mathrm{Ra}$ 和 ${ }^{228} \mathrm{Ra}$ 分布特征, 估算出底层水出现的高镭活度浓度的现象主要是由富含镭的海底地下水的排放造 成的 ${ }^{[11]}$. Zhang 等根据 ${ }^{226} \mathrm{Ra}$ 分布特征,结合海水的温度、盐度,估算出东海海域的海水由 $13.6 \%$ 黑潮表层水、 $42.7 \%$ 黑潮次表层水、22.0\%长江冲淡水以及 $21.6 \%$ 台湾暖流水构成 ${ }^{[12]}$. 孔凡翠等利用 ${ }^{226} \mathrm{Ra}$ 和 ${ }^{228} \mathrm{Ra}$ 计算出 青海湖北湾河流和地下水对湖泊的贡献率分别为 0.14 和 $0.13^{[13]}$, 青海湖西北岸通过地下水向湖泊排放通 量为 $7.67 \times 10^{6}$ 和 $(8.52 \pm 0.10) \times 10^{6} \mathrm{~m}^{3} / \mathrm{d}^{[14]}$. 在巴丹吉林沙漠湖泊利用镭同位素示踪了地下水的运移过程 以及湖泊沿岸地下水排放通量为 $1.68 \times 10^{5} \mathrm{~m}^{3} / \mathrm{d}^{[15]}$.

镭在水相和固相物质之间存在着可逆吸附行为,在淡水环境吸附在固相颗粒表面上,当固体颗粒物遇 到咸水时, 随着水体的盐度升高、离子强度增大, 䥻、镁等碱土金属离子对颗粒物上镭的竞争吸附作用增强, 导致其上吸附的 $\mathrm{Ra}$ 会发生解吸, 从而以溶解态 $\mathrm{Ra}^{2+}$ 的形式进人水体 ${ }^{[1]}$, 因而镭同位素能够用来示踪水体 相互作用过程 ${ }^{[7,16-17]}$. 在大柴旦盐湖区, 盐湖卤水盐度高达 $300 \%$, 外围地下水多为淡水, 从外围到湖滨岸区 再到到盐湖区水体盐度呈现增加的趋势, 存在一个明显的淡水和盐水的渐变区, 通过确定源、汇项 的 ${ }^{223,224,226,228} \mathrm{Ra}$ 活度值, 能够利用镭同位素示踪大柴旦湖区水循环过程.

学者们曾利用氡同位素和氢氧同位素示踪察尔汗湖区地下水一地表水之间的转换 ${ }^{[18]}$. 镭同位素在示踪 海洋、咸水湖和沙漠湖泊地下水排放研究中应用广泛, 技术成熟. 然而利用镭同位素示踪盐湖卤水区水循环 的研究相对薄弱. 因此, 本文将检测大柴旦盐湖、深部地下热水、浅层地下水、河流水、河流悬浮颗粒物中解 吸的镭同位素以及底部沉积物扩散的镭同位素等水体中镭同位素的活度, 分析其时空分布特征, 明确大柴 
旦盐湖中镭同位素的来源,探讨大柴旦周围水体水循环过程.

\section{1 地质背景}

大柴旦盐湖位于柴达木盆地东北缘的一个小山间盆地中, 呈肘状并由北向东南延伸, 外观呈不规则新 月形 (图 1). 其北部为达肯大坂山, 南部为绿梁山, 在大地构造位置上属于 “祁连山边缘凹陷带”, 区内构造 以断裂为主, 褶皱不发育, 岩浆活动频繁. 盆地外围山系分布元古界变质岩系、震旦系、寒武系、中下奥陶系、 石炭系、二叠系以及三叠系; 盆地边缘有小面积的白严系、侏罗系和第三纪分布; 第四系分布于山麓至湖盆 区, 自外向内依次为坡积、洪积冲积层和湖积层 ${ }^{[19]}$. 各时期的岩浆岩均有出露, 其中以中生代含电气石花岗 岩分布最为广泛. 各时期的花岗岩体大面积分布于大柴旦北部达肯大坂山区,包括前吕梁期花岗岩、加里东 期和海西期酸性至超基性岩及印支期含电气石斑状花岗岩和燕山期花岗斑岩. 达肯大坂山脉断裂带发育, 以大柴旦逆冲走滑断裂和宗务隆山逆冲断裂为主, 为山区裂隙潜水的形成提供了基本条件, 特别是为深循 环的地热水提供了良好条件,因而形成了大柴旦北部北麓温泉带 ${ }^{[20]}$.

据大柴旦气象站 $1970-2011$ 年资料, 多年平均气温 $2.4^{\circ} \mathrm{C}$; 气温最高值为 $31.5^{\circ} \mathrm{C}$ ( 2004 年), 气温最低值 为 $-34.2^{\circ} \mathrm{C}$ ( 1989 年); 多年平均降水量 $90 \mathrm{~mm}$, 多年平均蒸发量 $2123.0 \mathrm{~mm}$ (据中国气象数据网), 受西风环 流主控, 盆地中心干旱少雨. 大柴旦湖水面积及水深随着年份和季节的不同而变化, 最大水深通常不足 $1 \mathrm{~m}$, 盐湖卤水面积在 $35 \sim 45 \mathrm{~km}^{2}$ 范围内变化, 主要受到山区汇水盆地春季融水量和夏季降水量以及湖区蒸发量 的控制. 地表径流主要有八里沟河、大头羊沟河和温泉沟等, 无常年性河流人湖, 均为季节性河流. 其中, 八 里沟河长 $35 \mathrm{~km}$, 为补给河流中最大的一条, 在大柴旦镇东北 $1 \mathrm{~km}$ 处渗漏潜人地下, 穿过大柴旦镇以泉水出 露汇集成 2 条小河汇人大柴旦盐湖,其它河流均为短小的泉集河,集水域内泉眼达 80 多个. 温泉沟距离大 柴旦盐湖东北方向 $10 \mathrm{~km}$ 左右, 在花岗片麻岩断裂破碎带中分布一系列泉水溢出带, 大小温泉共计 87 个, 水 温一般为 $60 \sim 70^{\circ} \mathrm{C}$, 温泉水流量相对稳定, 温泉沟的温泉主要为融雪水补给, 其次为基岩裂隙水补给 ${ }^{[21]}$. 受 季节影响, 地表径流出山口后, 全部潜人地下, 转化为地下水, 并向大柴旦盐湖区汇集, 强烈的蒸发作用使大 柴旦盐湖成为水分排泄的主要途径. 在地质构造和沉积亚环境的控制下, 大柴旦湖盆的水文地质单元呈环 带状分布. 从山区至湖心, 分别为山区裂隙潜水区、山前冲洪积孔隙潜水区、沙坪浅层水区、盐滩晶间卤水区 和现代盐湖地表卤水区 ${ }^{[22]}$.

\section{2 样品与测试方法}

分别在 2016 年 3 月和 7 月采集大柴旦盐湖水样 33 个(图 2), 在温泉沟、八里沟、大头羊沟等地采集温 泉水 3 个 ( 2 个地表露头温泉水 (表层地下热水) 和 1 个 $70 \mathrm{~m}$ 以下深部温泉水 (深部地下热水)) 和冷泉水 5 个; 采集周围河流水样 10 个, 在大柴旦镇采集雨水样 1 个. 自然界水体中镭同位素的活度水平很低, 要想达 到检测限度需要利用锰纤维富集水体中的溶解态镭同位素 ${ }^{[35-38]}$. 用孔径为 $0.45 \mu \mathrm{m}$ 的醋酸纤维膜过滤采集 好的水样, 去除水中悬浮颗粒物和一些草类植物对锰纤维吸附作用的影响. 将 $15 \mathrm{~g}$ 左右制备好的锰纤维均 匀地封装在 PVC 样品柱中, 随后利用虹吸方式让水样以 $1 \sim 2 \mathrm{~L} / \mathrm{min}$ 的流速通过 PVC 样品柱来富集水体中 的镭. 实验表明, 当水体流速小于 $2 \mathrm{~L} / \mathrm{min}$ 时,纤维对镭同位素的富集效率可达 $99.7 \%{ }^{[23]}$. 河水、泉水和井水 等富集 $50 \mathrm{~L}$, 盐湖卤水和温泉水中镭的含量比较高, 每个样品富集 $10 \mathrm{~L}$. 对于高盐卢水, 由于镭同位素在高 盐的环境下对二氧化锰纤维的吸附效率较低, 每个样品进行 2 5 倍的蒸馏水稀释, 再进行富集, 并进行富集 效率测试. 具体方法是将两个含有二氧化锰纤维的柱子串联起来, 同时过滤样品, 第二个柱子里面的锰纤维 作为富集效率测试,经过测试本次研究富集效率为 $89.17 \%$. 辅助采集水化学样品 $100 \mathrm{~mL}$. 并使用便携式 HANNA 多参对每个样品的温度、溶解氧以及盐度进行野外原位测定. 在大柴旦盐湖中心用沉积物采样器取 3 个湖底沉积物柱子样品 (总重量大于 $10 \mathrm{~kg}$ ). 在洪水期过滤河水来采集河流悬浮颗粒物, 用盐度计测试河 水盐度值,在河流水盐度值最低的地方过滤河流悬浮颗粒物.

短半衰期镭同位素 ${ }^{223} \mathrm{Ra}$ 属于 ${ }^{235} \mathrm{U}$ 衰变系, 衰变后产生气态核素 ${ }^{219} \mathrm{Rn}\left(T_{1 / 2}=3.96 \mathrm{~s}\right)$, 继而又迅速衰变 为 ${ }^{215} \mathrm{Po}\left(T_{1 / 2}=150 \mathrm{~ms}\right),{ }^{224} \mathrm{Ra}$ 属于 ${ }^{232} \mathrm{Th}$ 衰变系, 衰变后产生气态核素 ${ }^{220} \mathrm{Rn}\left(T_{1 / 2}=55 \mathrm{~s}\right)$, 接着迅速衰变为 ${ }^{216} \mathrm{Po}$ $\left(T_{1 / 2}=1.76 \mathrm{~ms}\right),{ }^{223} \mathrm{Ra} 、{ }^{224} \mathrm{Ra}$ 核素母体和子体能够几分钟内在封闭体系中达到长久平衡 ${ }^{[24]}$. 同步延时计数 

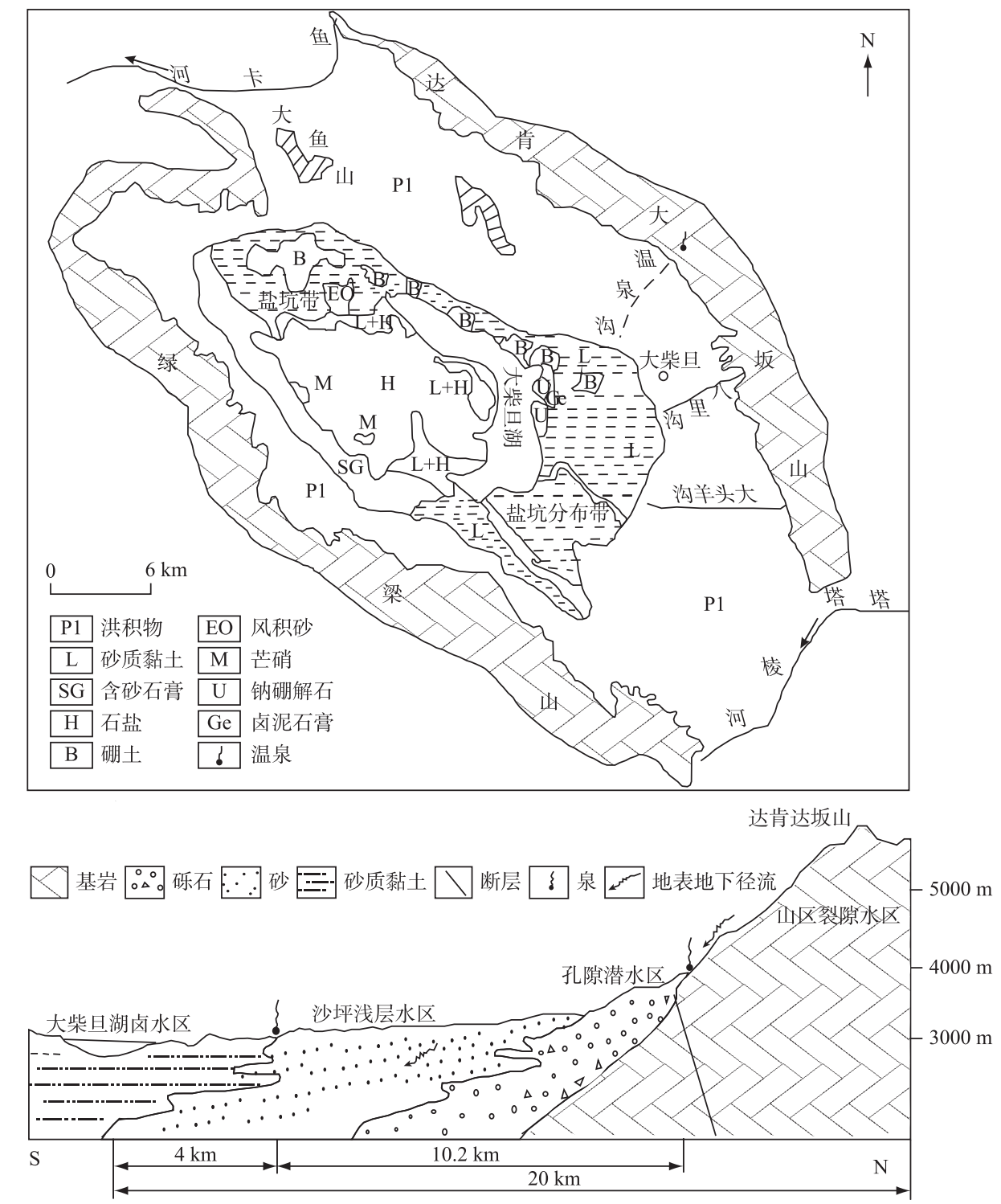

图 1 大柴旦盐湖湖区地质水文地质概图 (据文献 [20]修改)

Fig.1 Hydrogeology and geology of Da Qaidam salt lake (Modified according to the reference [20])

器 $(\operatorname{RaDeCC})$ 就是通过记录 ${ }^{219} \mathrm{Rn}$ 和 ${ }^{220} \mathrm{Rn}$ 同位素的 $\alpha$ 衰变信号来间接测定镭的放射性活度 ${ }^{[25]}$, 其单位为 $\mathrm{Bq}$ 或 $\mathrm{dpm}$, 表示每秒或每分钟衰变一次, $1 \mathrm{~Bq}=60 \mathrm{dpm}$. 短半衰期镭同位素采用同步延时计数器测试, 该仪器为 美国 Scientific Computer Instruments 公司生产的四通道同步延时计数器. 长半衰期的镭同位素采用高纯锗 $\gamma$ 能谱仪测试,该仪器为美国 ORTEC 公司生产,探测器为 GMX45P4 型.

\section{3 结果与讨论}

\section{1 大柴旦盐湖周围水体中镭同位素的分布特征}

研究区采样点的镭同位素活度见附表 I , 其中, 3 月份湖水中 ${ }^{223} \mathrm{Ra} 、{ }^{224} \mathrm{Ra} 、{ }^{226} \mathrm{Ra}$ 和 ${ }^{228} \mathrm{Ra}$ 活度变化范围分 别为 $(0.42 \pm 0.03) \sim(12.95 \pm 0.91) 、(25.04 \pm 1.26) \sim(581.00 \pm 29.05) 、(19.01 \pm 0.02) \sim(85.97 \pm 0.07)$ 和 $(144.5 \pm$ 


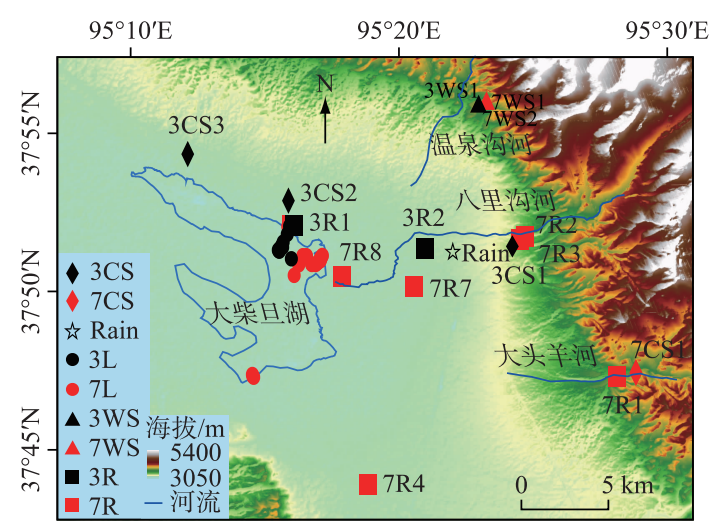

图 2 研究区采样点位置 (其中 $3 \mathrm{~L}$ 为 3 月湖水样品, $7 \mathrm{~L}$ 为 7 月湖水样品,

$3 \mathrm{WS}$ 为 3 月地下热水水样品, $7 \mathrm{WS}$ 为 7 月地下热水水样品, $3 \mathrm{CS}$ 为 3 月冷泉水样品, $7 \mathrm{CS}$ 为 7 月冷泉水样品, $3 \mathrm{R}$ 为 3 月河流样品, $7 \mathrm{R}$ 为 7 月河流样品, Rain 为雨水样品)

Fig. 2 The distribution of sampling sites in the studied area

$0.99) \sim(233.36 \pm 3.02) \mathrm{dpm} /(100 \mathrm{~L}) ; 7$ 月份湖水中 ${ }^{223} \mathrm{Ra} 、{ }^{224} \mathrm{Ra} 、{ }^{226} \mathrm{Ra}$ 和 ${ }^{228} \mathrm{Ra}$ 活度变化范围分别为 $(1.92 \pm$ $0.13) \sim(27.76 \pm 1.94) 、(10.66 \pm 0.53) \sim(331.24 \pm 16.56) 、(5.02 \pm 0.02) \sim(140.54 \pm 0.06) 、(16.84 \pm 0.08) \sim$ $(258.23 \pm 0.78) \mathrm{dpm} /(100 \mathrm{~L})$. 图 3 是大柴旦湖及周围水体中 3 月份和 7 月份镭同位素的活度分布, 可以看 出湖水中 ${ }^{223} \mathrm{Ra}$ 的活度比较低, ${ }^{224} \mathrm{Ra} 、{ }^{226} \mathrm{Ra}$ 和 ${ }^{228} \mathrm{Ra}$ 的活度比较高, 3 月份和 7 月份分布情况较为相似. 3 月份 采集的样品盐度变化范围为 $41.83 \%$ 240.41\%o, 7 月份采集的样品盐度变化范围为 $1.92 \%$ 240.00\% $\%$, 由于 盐湖水体不同结晶阶段以及补给源的变化, 造成湖水中盐度的变化范围比较大. 在 3 月份, 从岸边向湖中 心, 随着盐度的增加湖水中 ${ }^{223} \mathrm{Ra} 、{ }^{224} \mathrm{Ra} 、{ }^{226} \mathrm{Ra}$ 和 ${ }^{228} \mathrm{Ra}$ 活度表现出保守性的降低(图 4). 在沿岸近河口区, Ra 同位素活度都非常高, 而盐度相对较低. 7 月份采集的样品, ${ }^{223} \mathrm{Ra} 、{ }^{224} \mathrm{Ra} 、{ }^{226} \mathrm{Ra}$ 和 ${ }^{228} \mathrm{Ra}$ 活度先随着盐度的增 加而升高, 当盐度大于 $168.99 \%$ 时, 则随着盐度的增加而降低. 可能是在盐度低时镭发生解吸, 而盐度较高 时, 水体中的物质结晶, 镭与 $\mathrm{Ca}$ 和 $\mathrm{Ba}$ 元素共沉淀 ${ }^{[26]}$. 在同一区域湖体中, 随着离岸距离的增加, ${ }^{224} \mathrm{Ra}$ 表现 降低的趋势, ${ }^{223} \mathrm{Ra}$ 和 ${ }^{228} \mathrm{Ra}$ 升高趋势不明显, ${ }^{226} \mathrm{Ra}$ 则表现出升高的趋势, 受补给源、稀释、衰变等原因的影响, 反映了半衰期短 ${ }^{223} \mathrm{Ra}$ 和 ${ }^{224} \mathrm{Ra}$ 在混合区更容易衰减 ${ }^{[27]}$, 相反, 长半衰期 ${ }^{226} \mathrm{Ra}$ 和 ${ }^{228} \mathrm{Ra}$ 在解吸完全之后因与湖 内活度较低的水体混合而产生变化 ${ }^{[10]}$.

本文的地下水样来自温泉水和冷泉水, 盐度都很低, 范围在 $0.13 \% 0 ０ .90 \% 0$ 之间 (表 1 ). 冷泉取样深度 为 $0.1 \sim 2 \mathrm{~m}$, 属于浅层含水层的地下水, 温泉分别采集到自然露头(7WS1 和 3WS1) 和井深 70 $\mathrm{m}$ 处( 7WS2) 的样品, 水温在 $63.6 \sim 64.2^{\circ} \mathrm{C}$ 之间, 属于深部地下热水. 地下水中 ${ }^{223} \mathrm{Ra} 、{ }^{224} \mathrm{Ra} 、{ }^{226} \mathrm{Ra}$ 和 ${ }^{228} \mathrm{Ra}$ 的活度变化范围分 别为 $(1.81 \pm 0.01) \sim(51.13 \pm 3.58) 、(26.00 \pm 1.30) \sim(1924.00 \pm 96.24) 、(20.50 \pm 0.03) \sim(1190.49 \pm 0.07)$ 、 $(37.33 \pm 0.11) \sim(2404.44 \pm 2.42) \mathrm{dpm} /(100 \mathrm{~L})$. 随着盐度的增加, 地下水中 ${ }^{223} \operatorname{Ra} 、{ }^{224} \operatorname{Ra} 、{ }^{226} \operatorname{Ra}$ 和 ${ }^{228} \operatorname{Ra}$ 的活度 都表现出增加的趋势 (图 3 ). 深部地下热水中 ${ }^{223} \mathrm{Ra} 、{ }^{224} \mathrm{Ra} 、{ }^{226} \mathrm{Ra}$ 和 ${ }^{228} \mathrm{Ra}$ 的活度值平均分别是浅层地下水 中 ${ }^{223} \mathrm{Ra} 、{ }^{224} \mathrm{Ra} 、{ }^{226} \mathrm{Ra}$ 和 ${ }^{228} \mathrm{Ra}$ 活度值的 $11.38 、 34.72 、 24.09 、 27.66$ 倍,地下水中 Ra 同位素的活度比大柴旦湖湖 水和河流水中的 $\mathrm{Ra}$ 同位素的活度高, 变化范围较大. 深部地下热水 $(7 \mathrm{WS} 2)^{223} \mathrm{Ra} 、{ }^{224} \mathrm{Ra}$ 和 ${ }^{228} \mathrm{Ra}$ 的活度值是 表层地下热水 $(7 \mathrm{WS} 1)^{223} \mathrm{Ra} 、{ }^{224} \mathrm{Ra}$ 和 ${ }^{228} \mathrm{Ra}$ 活度值的 $3 \sim 4$ 倍, 而 ${ }^{226} \mathrm{Ra}$ 正好相反, 表层 ${ }^{226} \mathrm{Ra}$ 的活度值比深部 ${ }^{226}$ $\mathrm{Ra}$ 的活度值高, 表明 ${ }^{226} \mathrm{Ra}$ 具有明显的积累现象. 这是由于短半衰期 ${ }^{223} \mathrm{Ra} 、{ }^{224} \mathrm{Ra}$ 和 ${ }^{228} \mathrm{Ra}$ 易发生衰减, 而长半 衰期 ${ }^{226} \mathrm{Ra}$ 得到积累的原因,从而表明镭同位素的运移方向是从深部往上涌的过程.

在大柴旦湖研究区, 无常年性河流人湖, 主要河流分布在北部的达肯大坂山的大头羊沟和八里沟, 均为 季节性河流. 从表 1 中可以看出, 河流水的盐度非常小, 变化范围在在 $0 \sim 0.50 \% 0$ 之间, 河水水体中 ${ }^{223} \mathrm{Ra}$ 、 ${ }^{224} \mathrm{Ra} 、{ }^{226} \mathrm{Ra}$ 和 ${ }^{228} \mathrm{Ra}$ 活度变化范围分别为 $(0.30 \pm 0.01) \sim(35.79 \pm 2.51) 、(10.75 \pm 0.54) \sim(218.03 \pm 10.90)$ 、 $(4.45 \pm 0.02) \sim(89.63 \pm 0.09) 、(30.26 \pm 0.09) \sim(218.81 \pm 69.00) \mathrm{dpm} /(100 \mathrm{~L}),{ }^{223} \mathrm{Ra}$ 和 ${ }^{226} \mathrm{Ra}$ 变化范围较小, 

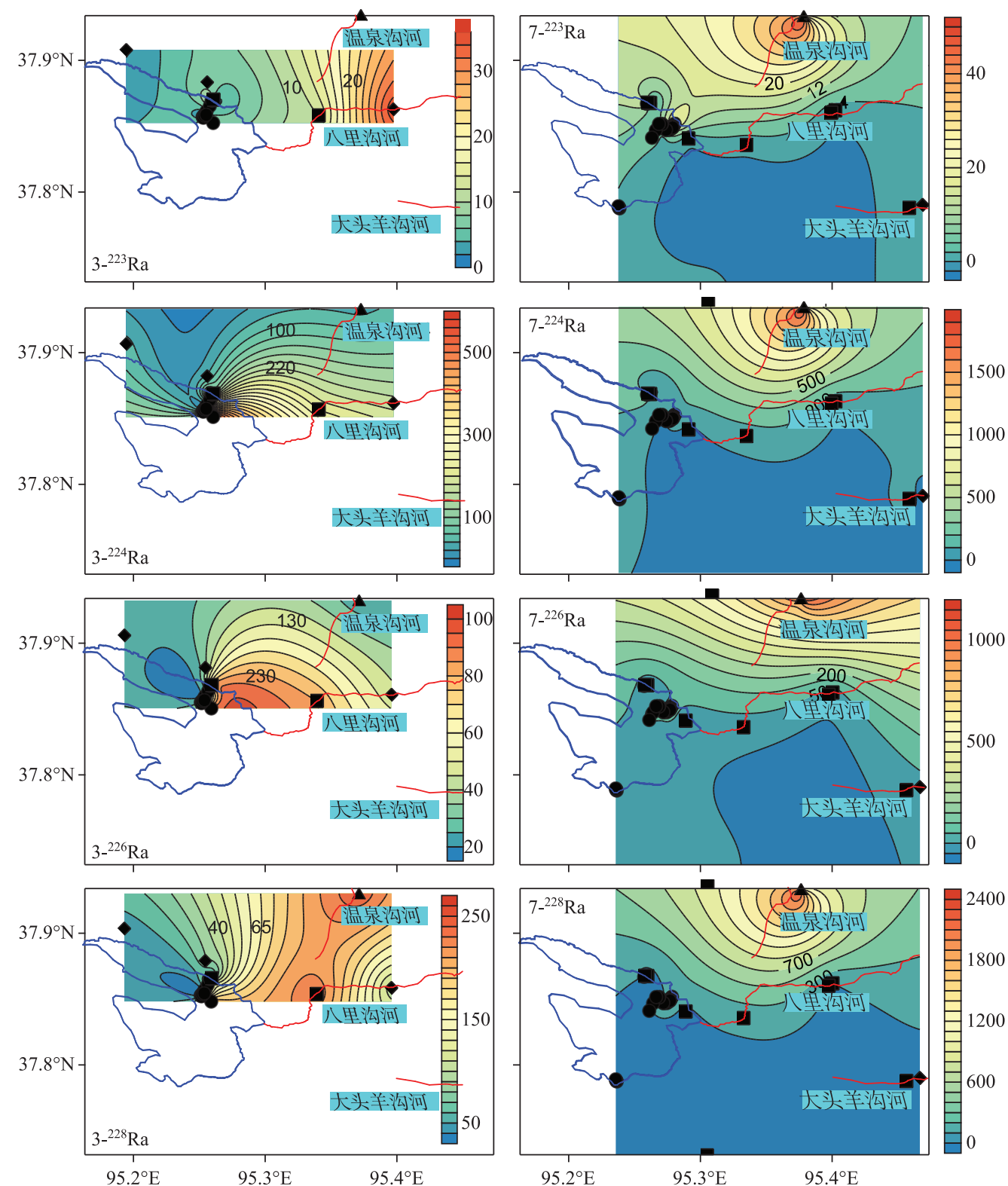

图 3 大柴旦盐湖水体中镭同位素活度 $(\mathrm{dpm} /(100 \mathrm{~L}))$ 的分布

Fig.3 The distribution of Radium isotopes activity of water in Da Qaidam salt lake

${ }^{224} \mathrm{Ra}$ 和 ${ }^{228} \mathrm{Ra}$ 和的活度值变化范围较大. 3 月份河水中 ${ }^{223} \mathrm{Ra},{ }^{224} \mathrm{Ra} 、{ }^{226} \mathrm{Ra}$ 和 ${ }^{228} \mathrm{Ra}$ 活度值比 7 月份河水中镭同 位素的活度值大. 河水中 ${ }^{223} \mathrm{Ra} 、{ }^{224} \mathrm{Ra}$ 和 ${ }^{228} \mathrm{Ra}$ 活度小于地下水中镭同位素的活度高于湖水中镭同位素的活 度. 河水中 ${ }^{226} \mathrm{Ra}$ 活度比湖水中 ${ }^{226} \mathrm{Ra}$ 的活度低, 这有可能是因为 ${ }^{226} \mathrm{Ra}$ 半衰期时间非常长, 在湖水中累积的缘 故. 从河口到河源水体中 ${ }^{223} \mathrm{Ra} 、{ }^{224} \mathrm{Ra}$ 和 ${ }^{228} \mathrm{Ra}$ 的活度值表现出增加的趋势, 而 ${ }^{226} \mathrm{Ra}$ 活度值恒定, 这可能是由 于水体滞留时间的不同, ${ }^{223} \mathrm{Ra} 、{ }^{224} \mathrm{Ra}$ 和 ${ }^{228} \mathrm{Ra}$ 的半衰期比较短, 随着滞留时间的增加而衰变的原因. $7 \mathrm{R} 7$ 站位 河水中镭同位素的活度值比河口和发源地河水中镭同位素的活度值高, 这是因为 7R7 站位在村庄的下游, 流经村庄后盐度变大, 河流中的颗粒物发生解吸, 使水体中镭同位素的活度值增加. 
表 1 河流悬浮颗粒物解吸 $\mathrm{Ra}$ 的活度值

Tab.1 The desorption Radium activity of suspended particulate matter of river

\begin{tabular}{cccccc}
\hline 样品编号 & 盐度 $/ \% 0$ & ${ }^{223} \mathrm{Ra} /(\mathrm{dpm} / \mathrm{kg})$ & ${ }^{224} \mathrm{Ra} /(\mathrm{dpm} / \mathrm{kg})$ & ${ }^{226} \mathrm{Ra} /(\mathrm{dpm} / \mathrm{kg})$ & ${ }^{228} \mathrm{Ra} /(\mathrm{dpm} / \mathrm{kg})$ \\
\hline R2-5 & 6.50 & $5.07 \pm 0.21$ & $113.36 \pm 3.4$ & $73.16 \pm 0.14$ & $235.80 \pm 0.50$ \\
R2-15 & 13.66 & $7.82 \pm 0.33$ & $168.72 \pm 5.06$ & $87.24 \pm 0.14$ & $311.30 \pm 0.53$ \\
R2-25 & 24.77 & $9.93 \pm 0.42$ & $319.84 \pm 9.60$ & $111.79 \pm 0.14$ & $344.04 \pm 0.52$ \\
R2-35 & 35.50 & $3.07 \pm 0.13$ & $318.51 \pm 9.56$ & $87.65 \pm 0.14$ & $375.18 \pm 0.52$ \\
R2-45 & 46.60 & $11.14 \pm 0.47$ & $195.94 \pm 5.88$ & $99.38 \pm 0.14$ & $331.05 \pm 0.52$ \\
R2-65 & 64.00 & $16.20 \pm 0.68$ & $59.17 \pm 1.77$ & $108.86 \pm 0.14$ & $430.14 \pm 0.53$ \\
R2-85 & 83.94 & $4.97 \pm 0.21$ & $242.63 \pm 7.28$ & $118.96 \pm 0.14$ & $392.44 \pm 0.53$ \\
R2-105 & 104.10 & $9.21 \pm 0.39$ & $283.31 \pm 8.50$ & $87.63 \pm 0.14$ & $255.18 \pm 0.50$ \\
R2-125 & 125.76 & $15.38 \pm 0.65$ & $177.98 \pm 5.34$ & $142.41 \pm 0.14$ & $413.70 \pm 0.53$ \\
R2-145 & 146.01 & $12.04 \pm 0.51$ & $190.27 \pm 5.71$ & $54.41 \pm 0.14$ & $265.22 \pm 0.51$ \\
R2-165 & 165.05 & $1.09 \pm 0.05$ & $257.45 \pm 10.12$ & $65.92 \pm 0.14$ & $252.13 \pm 0.51$ \\
R2-185 & 187.30 & $1.17 \pm 0.05$ & $140.06 \pm 6.60$ & $113.63 \pm 0.14$ & $270.17 \pm 0.51$ \\
R2-205 & 206.85 & $7.87 \pm 0.33$ & $11.24 \pm 0.34$ & $166.45 \pm 0.15$ & $341.29 \pm 0.53$ \\
R2-235 & 233.00 & $4.80 \pm 0.20$ & $46.65 \pm 3.80$ & $313.62 \pm 0.36$ & $733.37 \pm 1.27$ \\
\hline
\end{tabular}

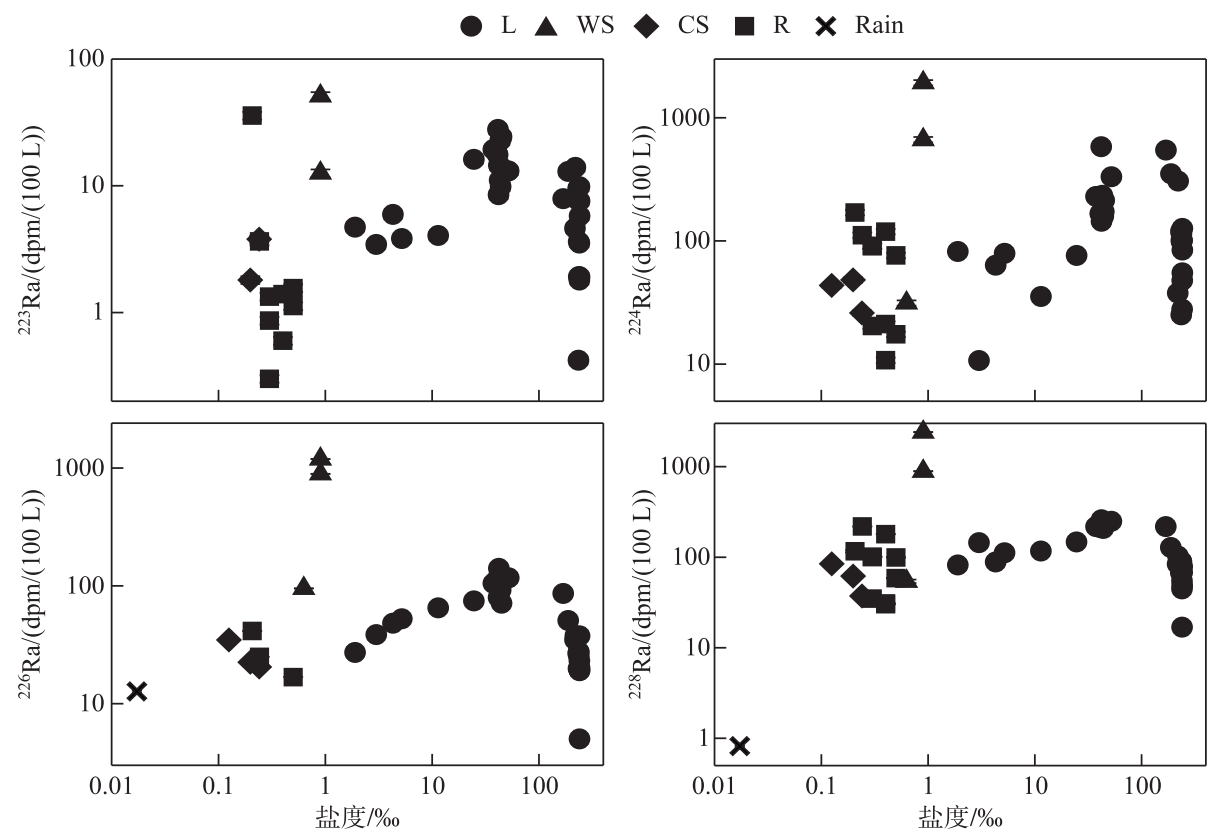

图 4 大柴旦盐湖及周围水体中镭同位素活度值与盐度的关系

Fig.4 The relationship between Radium isotopes activity and salinity of waters around Da Qaidam salt lake

\section{2 颗粒物中镭同位素的解吸特征}

镭在水相和固相物质之间存在着可逆吸附行为, 在淡水环境吸附在固相颗粒表面上, 当固体颗粒物遇 到咸水时, 随着水体的盐度升高、离子强度增大, 钙、镁等碱土金属离子对颗粒物上镭的竞争吸附作用增强, 导致其上吸附的 $\mathrm{Ra}$ 会发生解吸, 从而以溶解态 $\mathrm{Ra}^{2+}$ 的形式进人水体 ${ }^{[28]}$. Astwood 通过一系列的解吸实验得 出亚马逊河口区有 $40 \%$ 的 ${ }^{224} \mathrm{Ra}$ 来自悬浮颗粒的解吸 ${ }^{[29]}$. Mississippi 河和 Atchafalaya 河与海水混合过程中, 悬浮颗粒物上大约有 $50 \%$ 的 ${ }^{226} \mathrm{Ra}$ 和 ${ }^{228} \mathrm{Ra}$ 发生解吸, 其解吸活度达到 $18.00 \mathrm{dpm} /(100 \mathrm{~L})^{[11]}$. 苏妮等研究海 南东部㴼湖以及河口海底地下水发现, 万泉河口区 ${ }^{226} \mathrm{Ra}$ 的最大解吸量为 $3.81 \mathrm{dpm} /(100 \mathrm{~L})$, 八门湾地区 
${ }^{226} \mathrm{Ra}$ 的最大解吸量为 $3.42 \mathrm{dpm} /(100 \mathrm{~L})$, 解吸态的镭活度不可忽略 ${ }^{[30]}$. 由此可见, 河流悬浮颗粒物中解吸 的镭是水体中镭同位素的不可忽略的来源. 对悬浮颗粒物中镭的解吸进行研究能辨别水体中镭同位素的来 源、评估人湖水体停留时间、示踪沿岸地下水的排放通量推算研究提供科学依据.

本研究进行了悬浮颗粒物在不同盐度条件下的 Ra 的解吸实验, 具体实验步骤见文献 [ 31$]$, 测定结果见 表 $1 .{ }^{223} \mathrm{Ra}$ 的解吸活度值变化范围在 $(1.09 \pm 0.05) \sim(16.20 \pm 0.68) \mathrm{dpm} / \mathrm{kg}$ 之间,在盐度为 $64.00 \% 0$ 和 $125.76 \% 0$ 时 ${ }^{223} \mathrm{Ra}$ 的最大解吸活度值达到最大 $;{ }^{224} \mathrm{Ra}$ 的解吸活度值变化范围在 $(11.24 \pm 0.34) \sim(319.84 \pm 10.12) \mathrm{dpm} / \mathrm{kg}$ 之间, ${ }^{224} \mathrm{Ra}$ 的最大解吸活度值分别在盐度为 $24.77 \%$ 、 $104.10 \%$ 和 $165.05 \% 0$ 时; ${ }^{226} \mathrm{Ra}$ 的解吸活度值变化范围 在 $(54.41 \pm 0.14) \sim(313.62 \pm 0.36) \mathrm{dpm} / \mathrm{kg}$ 之间, ${ }^{228} \mathrm{Ra}$ 的解吸活度值变化范围在 $(235.80 \pm 0.50) \sim(733.37 \pm$ $1.27) \mathrm{dpm} / \mathrm{kg}$ 之间, ${ }^{226} \mathrm{Ra}$ 和 ${ }^{228} \mathrm{Ra}$ 的最大解吸活度值都发生在盐度为 $125.76 \%$ 时, ${ }^{226} \mathrm{Ra}$ 和 ${ }^{228} \mathrm{Ra}$ 具有相似的解 吸模式. 河流悬浮颗粒物中 ${ }^{224} \mathrm{Ra}$ 的解吸活度相对 ${ }^{226} \mathrm{Ra}$ 和 ${ }^{228} \mathrm{Ra}$ 的解吸活度较高, 这可能与 ${ }^{224} \mathrm{Ra}$ 半衰期短、 再生速率快有关.

镭同位素的解吸活度与盐度的关系见图 5. 从图中可以看出, 随着盐度的逐渐增加, Ra 同位素解吸活度 呈跳跃式增加趋势, 说明盐度越高, 悬浮颗粒上解吸下来的 Ra 越多. 从理论上分析, 悬浮颗粒物中镭的解吸 量不可能无限制地增加, 从图 4 的发展趋势看, 初步可以判断在盐度 $125 \%$ 附近时河流悬浮颗粒物中 ${ }^{223} \mathrm{Ra} 、{ }^{226} \mathrm{Ra}$ 和 ${ }^{228} \mathrm{Ra}$ 的解吸程度达到了最大值. 密西西比河解吸活度最大值发生在盐度为 $5.00 \%$ 时 ${ }^{[32]}$, 在海 洋沿岸研究中认为在盐度 $18.00 \%$ 左右镭的解吸最强烈 ${ }^{[33]}$. 但是都有一个相同的规律, 就是随着盐度升高, 镭同位素解吸量也随之增大,达到一个最大值后解吸量开始减小.
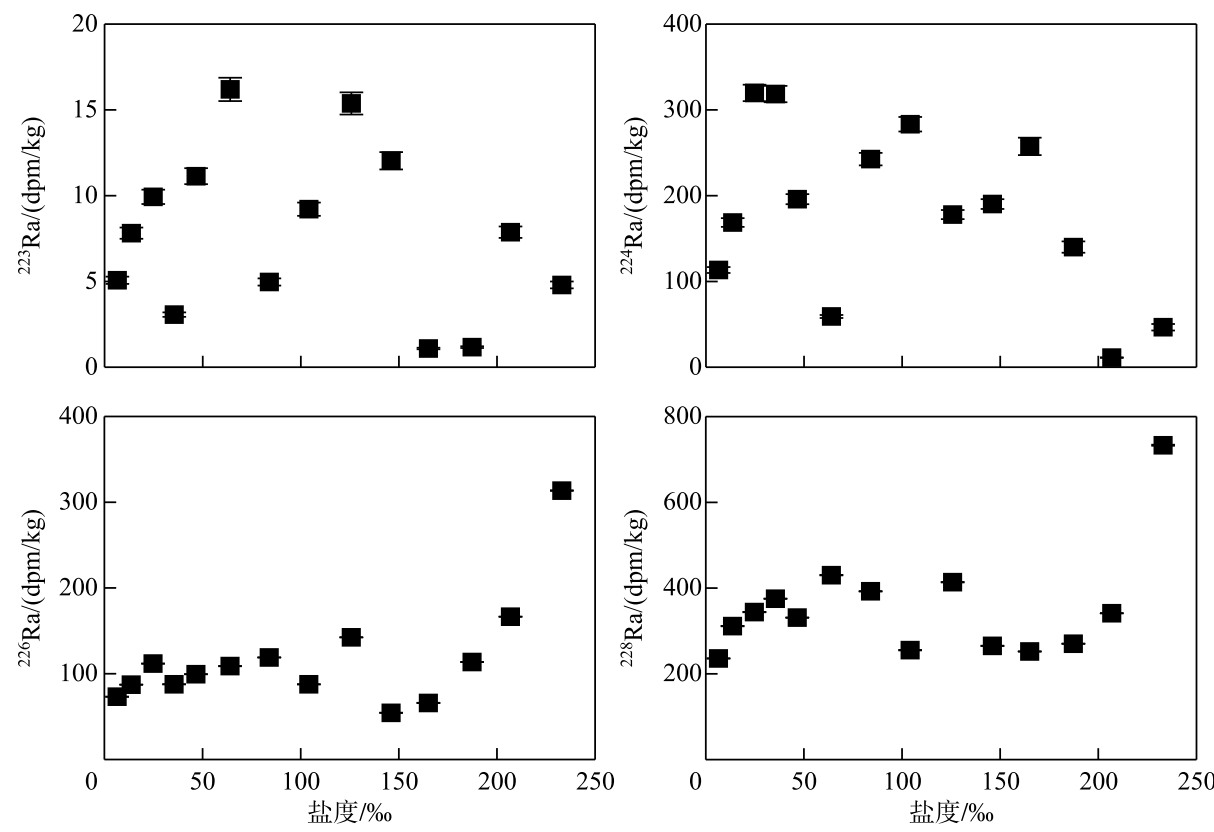

图 5 镭解吸活度与盐度的关系

Fig.5 The relationship between Radium desorption activity and salinity

\section{3 镭同位素的扩散特征}

自然界存在的镭同位素由沉积物中母体 U-Th 衰变而来. 河口表层沉积物中 U-Th 衰变产生的镭, 通常 使得沉积物间隙水中镭活度大于河口水中的镭活度, 在活度差作用下, 间隙水中的镭扩散到河口水体中, 成 为河口水中镭的来源之一 ${ }^{[34-35]}$. Beck 等对 Jamaica 湾潮间带的沉积物镭扩散实验结果显示, 沉积物中 ${ }^{223} \mathrm{Ra}$ 和 ${ }^{224} \mathrm{Ra}$ 的扩散通量分别为 0.02 和 $0.47 \mathrm{~Bq} /\left(\mathrm{m}^{2} \cdot \mathrm{d}\right)$, Jamaica 湾水体中的镭有 $4 \% \sim 11 \%$ 来源于海底沉积物的 扩散输人 ${ }^{[34]}$. Garcia-Solsona 等用意大利 Venice 瀉湖北部盐沼的沉积物做了扩散实验, 得到沉积物中 
${ }^{223} \mathrm{Ra} 、{ }^{224} \mathrm{Ra} 、{ }^{226} \mathrm{Ra}$ 和 ${ }^{228} \mathrm{Ra}$ 的扩散通量分别为 $0.02 、 0.53 、 0.28$ 和 $0.45 \mathrm{~Bq} /\left(\mathrm{m}^{2} \cdot \mathrm{d}\right)^{[35]}$. 沉积物中的镭向上覆水 体的扩散也是水体中镭同位素不可忽略的来源. 对沉积物镭的扩散量进行研究能准确辨别水体中镭同位素 的来源.

我们采集了湖底沉积物进行扩散培养实验. 把采集的表层沉积物分别放置到直径为 $36 \mathrm{~cm}$ 的敞口塑料 桶中, 厚度 $5 \sim 10 \mathrm{~cm}$, 水深约为 $30 \mathrm{~cm}$, 水温在 $22 \sim 26^{\circ} \mathrm{C}$ 之间变化. 对沉积物进行不同时段的扩散培养实验, 具体实验流程可见文献 [31]. 为了使其充分稳定下来, 在实验之前将该样品放置 2 个月, 因为在取样和搬运 过程中会对样品产生一定扰动, 对测量结果有影响. 我们对湖底沉积物样品进行了 $0.5 、 1 、 2 、 3 、 5 、 7 、 10 、 12 、$ $16 、 27 \mathrm{~d}$ 的扩散培养. 不同培养时间段湖底沉积物 Ra 扩散量见表 2. 将这些实测数据做成培养时间与扩散通 量的散点图 (图 5). 由于镭同位素的解吸反应在几秒到几小时就可以完成, 当培养时间较短时, Ra 的活度普 遍偏高, 且没有规律可循 ${ }^{[36]}$, 因此, 主要是培养刚开始时镭的活度主要是沉积物中原有镭同位素的解吸出来 的, 扩散出来的镭不明显. 过一段时间后, 沉积物间隙水中 Ra 活度与新加人的无镭河口水 Ra 活度之差达到 最大, Ra 活度梯度也达到最大, 这就会促使分子扩散作用加剧, 沉积物孔隙水中镭同位素的扩散作用开始增 强,孔隙水中镭同位素浓度开始增大.

表 2 湖底沉积物 Ra 扩散*

Tab.2 Activity of diffusion Radium from lake sediment

\begin{tabular}{ccccccc}
\hline 扩散培养时间 & 时间 $/ \mathrm{h}$ & 面积 $/ \mathrm{m}^{2}$ & ${ }^{223} \mathrm{Ra} / \mathrm{dpm}$ & ${ }^{224} \mathrm{Ra} / \mathrm{dpm}$ & ${ }^{226} \mathrm{Ra} / \mathrm{dpm}$ & ${ }^{228} \mathrm{Ra} / \mathrm{dpm}$ \\
\hline $0.5 \mathrm{~d}$ & 12 & 0.13 & $1.36 \pm 0.07$ & $7.40 \pm 0.37$ & $7.61 \pm 0.01$ & $18.03 \pm 0.02$ \\
$1 \mathrm{~d}$ & 36 & 0.13 & $2.16 \pm 0.11$ & $15.49 \pm 0.40$ & $12.98 \pm 0.01$ & $32.42 \pm 0.02$ \\
$2 \mathrm{~d}$ & 84 & 0.13 & $3.62 \pm 0.18$ & $25.28 \pm 0.49$ & $17.88 \pm 0.01$ & $46.40 \pm 0.02$ \\
$3 \mathrm{~d}$ & 156 & 0.13 & $4.50 \pm 0.23$ & $33.93 \pm 0.43$ & $21.86 \pm 0.01$ & $58.75 \pm 0.02$ \\
$5 \mathrm{~d}$ & 276 & 0.13 & $5.10 \pm 0.25$ & $43.40 \pm 0.47$ & $25.09 \pm 0.01$ & $69.59 \pm 0.02$ \\
$7 \mathrm{~d}$ & 444 & 0.13 & $5.77 \pm 0.29$ & $60.36 \pm 0.85$ & $26.86 \pm 0.01$ & $78.59 \pm 0.02$ \\
$10 \mathrm{~d}$ & 684 & 0.13 & $7.09 \pm 0.35$ & $74.81 \pm 0.72$ & $28.31 \pm 0.01$ & $85.12 \pm 0.02$ \\
$12 \mathrm{~d}$ & 972 & 0.13 & $9.00 \pm 0.45$ & $92.66 \pm 0.89$ & $30.78 \pm 0.01$ & $90.97 \pm 0.02$ \\
$16 \mathrm{~d}$ & 1356 & 0.13 & $10.95 \pm 0.55$ & - & 33.26 & $100.46 \pm 0.02$ \\
$27 \mathrm{~d}$ & 2004 & 0.13 & $15.31 \pm 0.77$ & $147.21 \pm 2.73$ & 38.09 & $110.90 \pm 0.02$ \\
$J /\left(\mathrm{dpm} /\left(\mathrm{m}^{2} \cdot \mathrm{h}\right)\right)$ & & & 0.13 & 4.72 & 0.10 & 0.32 \\
\hline
\end{tabular}

$* J$ 为单位面积、单位时间内镭的扩散通量.

从图 5 可以看出, ${ }^{224} \mathrm{Ra}$ 的再生速率快, 添加到上覆水体中的 ${ }^{224} \mathrm{Ra}$ 与水体中 ${ }^{224} \mathrm{Ra}$ 的衰变损失一直未达到 平衡, 表现为散点连线一直呈增加趋势. 而对长周期的 ${ }^{226} \mathrm{Ra}$ 和 ${ }^{228} \mathrm{Ra}$ 来讲, 由于其半衰期很长, 致使上覆水体 中的 ${ }^{226} \mathrm{Ra}$ 的添加十分缓慢, 所以短时间内不会出现扩散输人与衰变之间的平衡, 在图上的反映就是散点基 本上缓慢增加趋势 (图 6).

我们假设上覆水体中只存在沉积物扩散和放射衰变, 并且沉积物释放出的 Ra 大于放射性衰变损失的 量, 也就是说在沉积物的上覆水体中 Ra 活度变化的结果是一个正值, 那么这个值可以表示为:

$$
\mathrm{d} I / \mathrm{d} t=\left(J_{\text {diff }} \cdot A_{\text {surf }}\right)-\lambda \cdot I
$$

通过积分可以得到：

$$
I=\left(J_{\text {diff }} \cdot A_{\text {surf }}-\mathrm{e}^{-\lambda t}\right) / \lambda
$$

而上覆水体中的镭同位素的活度随时间的变化可以表达成如下公式 ${ }^{[34]}$ :

$$
I_{t}=\left(J_{\text {diff }} \cdot A_{\text {surf }} / \lambda\right)\left(1-\mathrm{e}^{-\lambda t}\right)+I_{0} \mathrm{e}^{-\lambda t}
$$

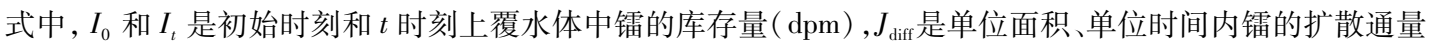
$\left(\mathrm{dpm} /\left(\mathrm{m}^{2} \cdot \mathrm{d}\right)\right), \lambda$ 是镭的衰变常数 $\left(\mathrm{h}^{-1}\right), A_{\text {surf }}$ 是培养样品的面积 $\left(0.13 \mathrm{~m}^{2}\right)$. 本次实验使用的是无镭水, 所 以认为 $I_{0}=0$, 公式 $(3)$ 可以变为:

$$
I_{t}=\left(J_{\text {diff }} \cdot A_{\text {surf }} / \lambda\right)\left(1-\mathrm{e}^{-\lambda t}\right)
$$

对于长半衰期 ${ }^{226} \mathrm{Ra}$ 和 ${ }^{228} \mathrm{Ra}$ 来说, 由于其半衰期很长, 在培养时间 $t$ 范围由放射衰变损失的量可以忽略. 

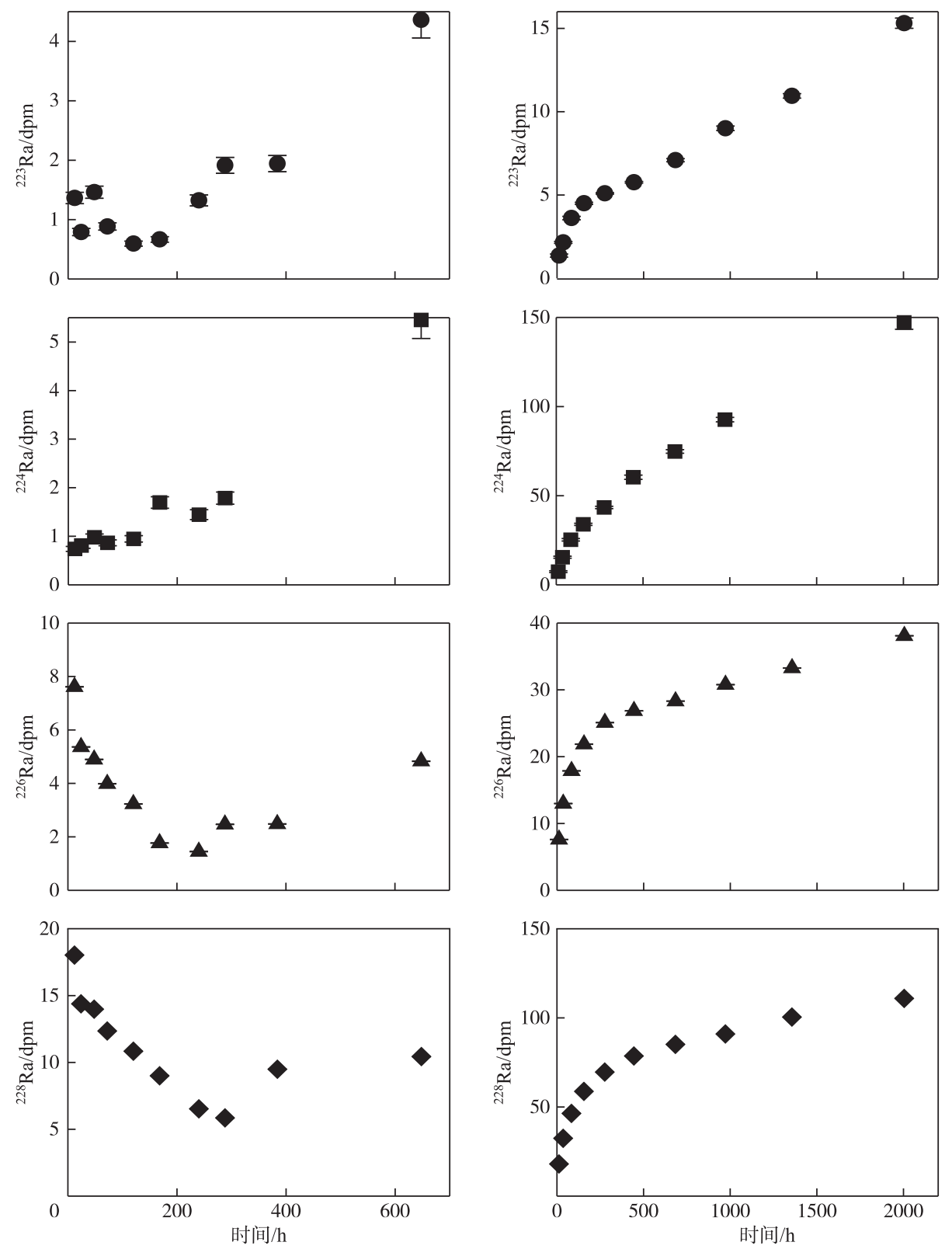

图 6 大柴旦盐湖湖底沉积物 Ra 扩散量与时间的关系

Fig. 6 The relationship between diffusion flux of Radium of the bottom sediment in the Da Qaidam salt lake and time

因此 ${ }^{226} \mathrm{Ra}$ 和 ${ }^{228} \mathrm{Ra}$ 活度随时间的变化公式为:

$$
I_{t}=J_{\text {diff }} \cdot A_{\text {surf }} \cdot t
$$

根据理论公式 (4) 和 (5) 用拟合法来确定湖底部沉积物培养样的 $J_{\text {diff }}$ 值, 得到湖底沉积物样品的 Ra 扩 散速率, 见表 2. 湖底沉积物 ${ }^{223} \mathrm{Ra} 、{ }^{224} \mathrm{Ra} 、{ }^{226} \mathrm{Ra}$ 和 ${ }^{228} \mathrm{Ra}$ 扩散速率分别是 $0.13 、 4.72 、 0.10$ 和 $0.32 \mathrm{dpm} /\left(\mathrm{m}^{2} \cdot \mathrm{h}\right)$. ${ }^{224} \mathrm{Ra}$ 的扩散速率比 ${ }^{226} \mathrm{Ra}$ 和 ${ }^{228} \mathrm{Ra}$ 高出很多, 可能是由于 ${ }^{224} \mathrm{Ra}$ 的半衰期短, 扩散速率要比 ${ }^{226} \mathrm{Ra}$ 和 ${ }^{228} \mathrm{Ra}$ 快. ${ }^{226} \mathrm{Ra}$ 的扩散通量比 ${ }^{228} \mathrm{Ra}$ 小, 是由于 ${ }^{226} \mathrm{Ra}$ 再生速率很慢, 上覆水体中 ${ }^{226} \mathrm{Ra}$ 的添加十分缓慢而造成的. 
沉积物扩散出的镭同位素通量 $\left(I_{\text {diff }}\right)$ 可以用下式进行计算:

$$
I_{\text {diff }}=J_{\text {diff }} \cdot A_{\text {sed }} \cdot H_{\text {day }}
$$

式中, $J_{\text {diff }}$ 是单位面积、单位时间内沉积物扩散的镭通量 $\left(\mathrm{dpm} /\left(\mathrm{m}^{2} \cdot \mathrm{h}\right)\right), A_{\mathrm{sed}}$ 是表层沉积物的覆盖面积 $\left(\mathrm{m}^{2}\right), H_{\mathrm{day}}$ 是每天的小时数 $(24 \mathrm{~h})$. 研究区域大柴旦盐湖水体覆盖面积为 $35 \sim 45 \mathrm{~km}^{2}$. 根据公式 (6) 可以算 出湖底沉积物每天释放出的 ${ }^{223} \mathrm{Ra} 、{ }^{224} \mathrm{Ra} 、{ }^{226} \mathrm{Ra}$ 和 ${ }^{228} \mathrm{Ra}$ 的通量分别为 $1.08 \times 10^{8} 、 3.96 \times 10^{9} 、 8.29 \times 10^{7} 、 2.67 \times 10^{8}$ $\mathrm{dpm}$, 如果换成浓度的话, 分别是 $0.31 、 11.32 、 0.24$ 和 $0.76 \mathrm{dpm} /(100 \mathrm{~L})$, 与河流和地下水中的活度相比, 非常 小, 比误差值还要小,所以几乎可以忽略.

\section{4 大柴旦盐湖中镭同位素的来源和水循环过程}

3.4.1 大柴旦盐湖中镭同位素的来源 Moore 提出海洋沿岸水体中的镭来源包括海洋水中的镭、河流水中的 镭、河流沉积物解吸的镭、沉积物间隙水扩散的镭和地下水中的镭 ${ }^{[6]}$. 水体中镭同位素的迁出主要途径有: 1) 镭同位素的自身衰变;2) 吸附溶解态 Ra 的自然沉降;3) 镭同位素可以通过生物过程被吸收到海洋生物体 的有机质外壳、硅质或钙质硬组织中, 由此迁出水体中;4) 当 $\mathrm{Fe} 、 \mathrm{Mn}$ 等元素发生氧化还原反应生成氧化物沉 淀时, 周围水体中溶解态 $\mathrm{Ra}$ 被清除. 对 ${ }^{223} \mathrm{Ra} 、{ }^{224} \mathrm{Ra} 、{ }^{226} \mathrm{Ra}$ 和 ${ }^{228} \mathrm{Ra}$ 来说, 虽然它们的地球化学行为很相似, 但 是它们的半衰期不同, 导致它们的活度值产生的速率不同. 因此, 不同来源的镭其 $\mathrm{Ar}\left({ }^{223} \mathrm{Ra} /{ }^{226} \mathrm{Ra}\right)$ 、 $\operatorname{Ar}\left({ }^{224} \mathrm{Ra} /{ }^{226} \mathrm{Ra}\right) 、 \operatorname{Ar}\left({ }^{224} \mathrm{Ra} /{ }^{228} \mathrm{Ra}\right) 、 \operatorname{Ar}\left({ }^{228} \mathrm{Ra} /{ }^{226} \mathrm{Ra}\right)$ 活度比值不一样, 而相同来源的镭其 $\operatorname{Ar}\left({ }^{223} \mathrm{Ra} /{ }^{226} \mathrm{Ra}\right)$ 值、 $\operatorname{Ar}\left({ }^{224} \mathrm{Ra} /{ }^{226} \mathrm{Ra}\right)$ 值、 $\operatorname{Ar}\left({ }^{224} \mathrm{Ra} /{ }^{228} \mathrm{Ra}\right)$ 值、 $\operatorname{Ar}\left({ }^{228} \mathrm{Ra} /{ }^{226} \mathrm{Ra}\right)$ 值应该相同. 但是由于 ${ }^{223} \mathrm{Ra}$ 和 ${ }^{224} \mathrm{Ra}$ 的半衰期比较 短, 在迁移转化过程中会衰变, 因此在不同水体中分布模式不稳定. 而 ${ }^{228} \mathrm{Ra}$ 和 ${ }^{226} \mathrm{Ra}$ 半衰期长, 在不同水体中 的分布模式相对稳定. 图 6 显示了所有样品中短半衰期镭同位素与长半衰期镭同位素活度值之间的关系 图, 如果只有一种镭的来源, 并且这个来源的镭输人到大柴旦湖中, 那么在这个图中所有的样品都应该成一 条直线. 从图 7 可以看出, 大柴旦盐湖湖水中 ${ }^{226} \mathrm{Ra}$ 和 ${ }^{228} \mathrm{Ra}$ 的分布介于深部地下热水、浅层地下水和河水之 间,表明大柴旦湖水中镭同位素是三者混合而成.
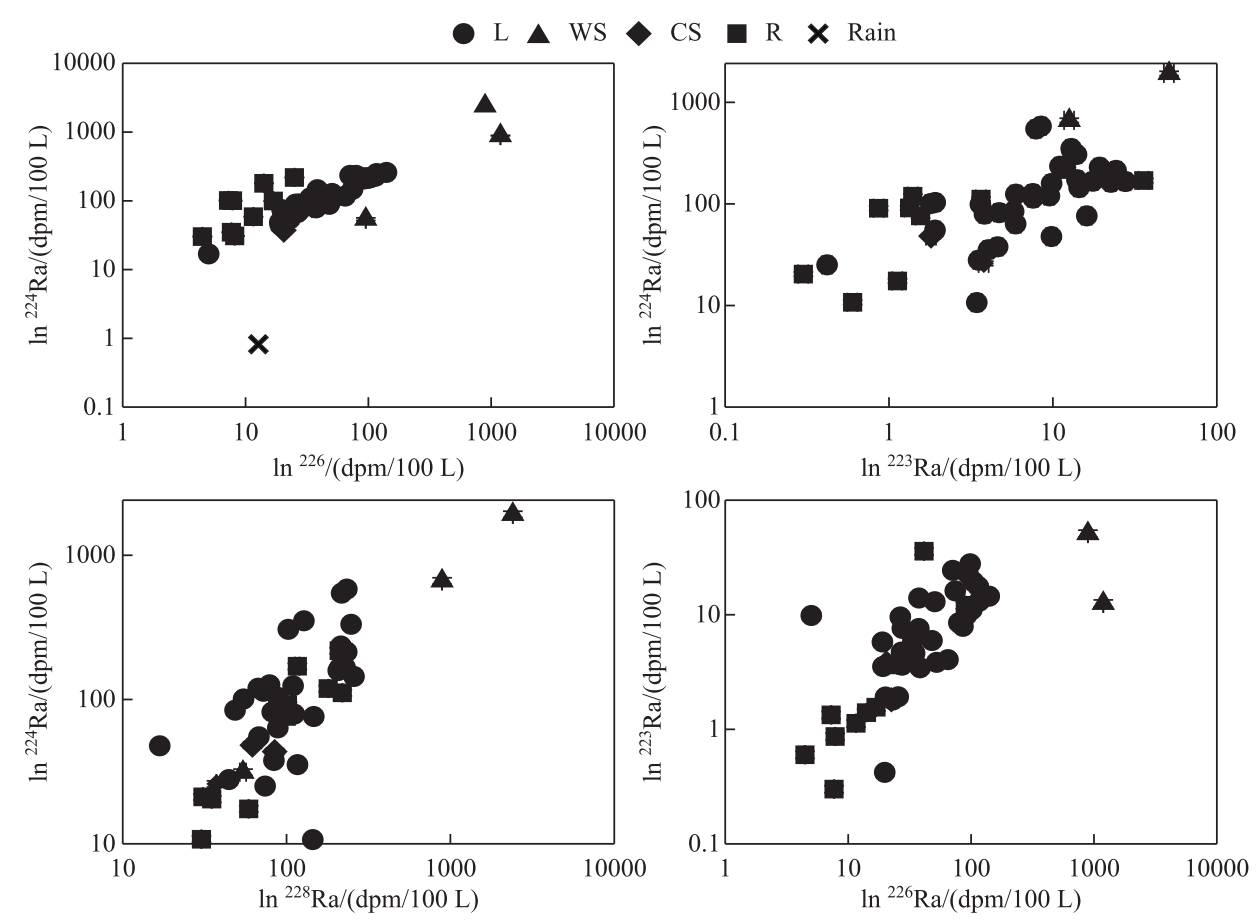

图 7 水体中镭同位素活度之间的关系

Fig.7 The relationship between ${ }^{223} \mathrm{Ra},{ }^{224} \mathrm{Ra},{ }^{228} \mathrm{Ra}$ and ${ }^{226} \mathrm{Ra}$ isotopes activity in different waters 
不同来源的镭同位素会形成不同 $\operatorname{Ar}\left({ }^{228} \mathrm{Ra} /{ }^{226} \mathrm{Ra}\right)$ 值, 相同来源的镭同位素应该会有相同 $\operatorname{Ar}\left({ }^{228} \mathrm{Ra} /\right.$ $\left.{ }^{226} \mathrm{Ra}\right)$ 值. 从地下水中 ${ }^{226} \mathrm{Ra}$ 和 ${ }^{228} \mathrm{Ra}$ 线性拟合关系图, 得到深部地下热水中 $\operatorname{Ar}\left({ }^{228} \mathrm{Ra} /{ }^{226} \mathrm{Ra}\right)$ 值为 $2.70(n=1)$, 浅层地下水中 $\operatorname{Ar}\left({ }^{228} \mathrm{Ra} /{ }^{226} \mathrm{Ra}\right)$ 为 $2.43(n=5)$, 而表层地下热水中 $\operatorname{Ar}\left({ }^{228} \mathrm{Ra} /{ }^{226} \mathrm{Ra}\right)$ 值为 $0.66(n=2)$, 深部地 下热水与浅层地下水具有相似的 $\operatorname{Ar}\left({ }^{228} \mathrm{Ra} /{ }^{226} \mathrm{Ra}\right)$ 值, 表明深部地下热水与浅层地下水的来源相同, 深部地 下热水与浅层地下水都代表了地下水, 因此地下水来源均一、稳定 ${ }^{[29]}$. 表层地下热水样品 7WS1 的 $\operatorname{Ar}\left({ }^{228} \mathrm{Ra} /{ }^{226} \mathrm{Ra}\right)_{\mathrm{G}}(0.66, n=2)$ 与湖湖水中 $\operatorname{Ar}\left({ }^{228} \mathrm{Ra} /{ }^{226} \mathrm{Ra}\right)_{\mathrm{S}}$ (平均 $\left.2.58, n=33\right)$ 相比,其值非常低,这说明了表 层地下热水中低的 $\operatorname{Ar}\left({ }^{228} \mathrm{Ra} /{ }^{226} \mathrm{Ra}\right)_{\mathrm{G}}$ 不能解释湖水中的 $\operatorname{Ar}\left({ }^{228} \mathrm{Ra} /{ }^{226} \mathrm{Ra}\right)_{\mathrm{s}}$, 而深部地下热水和浅层地下水样 品 ${ }^{228} \mathrm{Ra}{ }^{226} \mathrm{Ra}$ 活度比值都能够解释湖表水中的活度比值. 由于深部地下热水和浅层地下水中 ${ }^{228} \mathrm{Ra} /{ }^{226} \mathrm{Ra}$ 活 度比值与湖表水相接近, 我们认为深部地下热水和浅层地下水带来的镭可能是湖表水中的镭的主要来源.

从大柴旦盐湖水 ${ }^{226} \mathrm{Ra}$ 的分布与盐度的关系图 (图 3) 可以看出, ${ }^{226} \mathrm{Ra}$ 随盐度的分布特征显示了非保守 的添加过程, 这表明大柴旦湖湖水中镭的来源具有复杂性, 除了地下水输人带来的镭, 还可能有其他来源.

排人到大柴旦湖中的河水盐度比较低, 大柴旦湖水盐度很高, 由于河水的带人而使得大柴旦湖边盐度 变得较低一些. 在这个过程中,大柴旦湖的咸水对河口区悬浮颗粒物具有解吸作用,说明大柴旦湖咸水对河 口区悬浮颗粒物中镭的解吸可能是另外一个镭的来源. 河流贡献的镭包括两个部分: 溶解态 Ra 和悬浮颗粒 态 Ra 的解吸 ${ }^{[13]}$. 采样期间大柴旦湖周围主要注人河流是北岸大头羊沟和八里沟的季节性河流. 河流溶解 态 ${ }^{223} \mathrm{Ra} 、{ }^{224} \mathrm{Ra} 、{ }^{226} \mathrm{Ra}$ 和 ${ }^{228} \mathrm{Ra}$ 的活度变化范围分别为 $(0.3 \pm 0) \sim(12.09 \pm 0.85) 、(10.75 \pm 0.54) \sim(218.03 \pm$ $10.90) 、(4.45 \pm 0.02) \sim(89.63 \pm 0.05)$ 和 $(30.26 \pm 0.08) \sim(218.81 \pm 0.70) \mathrm{dpm} /(100 \mathrm{~L})$.

通过实验河流悬浮颗粒物解吸下来的镭的活度, 我们可以推算河流中解吸态镭的活度值. 假定: (1) 悬 颗粒物上的 Ra 释放后, 颗粒物沉降到河床底部; (2) 悬浮颗粒物和沉积物具有相同的交换能力. 则解吸态 $R a_{\mathrm{D}}(\mathrm{dpm} /(100 \mathrm{~L}))$ 可按下式进行计算:

$$
R a_{\mathrm{D}}=R a_{\text {susd }} \cdot C
$$

式中, $R a_{\text {susd }}$ 代表悬浮颗粒物解吸出来的镭的活度, $C$ 表示河流中悬浮颗粒物的含量 (含砂量), 通过对河流 悬浮颗粒物解吸实验, 我们得到了河流悬浮颗粒物解吸的镭活度值 $(\mathrm{dpm} /(100 \mathrm{~L}))$. 得到 ${ }^{223} \mathrm{Ra} 、{ }^{224} \mathrm{Ra} 、{ }^{226} \mathrm{Ra}$ 和 ${ }^{228} \mathrm{Ra}$ 的平均解吸量分别为 $(7.84 \pm 0.33) 、(180.37 \pm 5.93) 、(116.51 \pm 0.16) 、(353.64 \pm 0.57) \mathrm{dpm} / \mathrm{kg}$. 由于没 有大头羊沟和八里沟河水含沙量数据, 我们取周边河流鱼卡河和塔塔棱河含沙量数据, 但是鱼卡河和塔塔 棱河都不注人大柴旦湖. 鱼卡河多年平均含沙量为 $1.55 \mathrm{~kg} / \mathrm{m}^{3}$, 塔塔棱河多年平均含沙量为 $0.54 \mathrm{~kg} / \mathrm{m}^{3}$, 大 柴旦周围河流多年平均含沙量非常低 ${ }^{[37]}$. 我们按河流含沙量平均值 $C=1.05 \mathrm{~kg} / \mathrm{m}^{3}$ 来算, 得到河流中解吸 态 ${ }^{223} \mathrm{Ra} 、{ }^{224} \mathrm{Ra} 、{ }^{226} \mathrm{Ra}$ 和 ${ }^{228} \mathrm{Ra}$ 的活度值分别为 $(8.23 \pm 0.35) 、(189.38 \pm 6.22) 、(122.33 \pm 0.17)$ 和 (371.33 \pm 0.60$)$ $\mathrm{dpm} /(100 \mathrm{~L})$. 如果从 Ra 的最大解吸位置 3R1、7R5 起, 那么湖水中镭的分布遵循咸淡水保守混合, 在河口 区湖水中站位 $3 \mathrm{~L} 10$ 和 $7 \mathrm{~L} 18$ 不可能出现 ${ }^{223} \mathrm{Ra} 、{ }^{224} \mathrm{Ra} 、{ }^{226} \mathrm{Ra}$ 和 ${ }^{228} \mathrm{Ra}$ 活度值为 $(8.48 \pm 0.59) 、(581.00 \pm 29.05)$ 、 $(79.56 \pm 0.04) 、(233.36 \pm 1.78)$ 和 $(13.95 \pm 0.98) 、(305.61 \pm 15.28) 、(37.74 \pm 0.04) 、(102.65 \pm 0.52) \mathrm{dpm} /(100$ L), 这说明在湖水中必然存在除了河流注人带来的 Ra 之外, 还存在额外添加来源. 河水中溶解态和解吸 态 ${ }^{223} \mathrm{Ra} 、{ }^{224} \mathrm{Ra} 、{ }^{226} \mathrm{Ra}$ 和 ${ }^{228} \mathrm{Ra}$ 的总活度值明显高于湖水中 ${ }^{223} \mathrm{Ra} 、{ }^{224} \mathrm{Ra} 、{ }^{226} \mathrm{Ra}$ 和 ${ }^{228} \mathrm{Ra}$ 的活度值, 因此河水中携带 的镭同位素对湖水中的镭同位素的活度值的贡献不能忽略.

大柴旦湖湖水中镭的来源还有可能是沉积物间隙水中 $\mathrm{Th}$ 衰变生成的 Ra, 在 $\alpha$ 反冲作用下进人沉积物 间隙水,然后扩散到上覆水体中. 沿岸湖水体中 ${ }^{226} \mathrm{Ra}$ 的来源包括沉积物扩散和与地下咸水交换的镭 ${ }^{[6]}$, 从 沉积物中释放后, 颗粒物上的 ${ }^{226} \mathrm{Ra}$ 产生的速率非常慢. 在海洋中, 随着深度的增加 ${ }^{226} \mathrm{Ra}$ 呈现降低的趋势, 达 到 $3000 \mathrm{~m}$ 深度后随着深度的增加 ${ }^{226} \mathrm{Ra}$ 呈现增加的趋势, 这是因为底部沉积物扩散解吸出来镭的缘故. 有可 能大柴旦湖湖底沉积物再悬浮会解吸出很小量的 $\mathrm{Ra}$, 其中沉积物中扩散产生的 ${ }^{226} \mathrm{Ra}$ 的过程如下:

$$
A^{226} \operatorname{Ra}=A^{230} \operatorname{Th}\left(1-\mathrm{e}^{-\lambda_{22 b^{t}}}\right)
$$

式中, $\lambda_{226}$ 是 ${ }^{226} \mathrm{Ra}$ 的衰变系数 $\left(4.33 \times 10^{-4} \mathrm{a}\right), A$ 是核素母体和子体的活度. $A^{226} \mathrm{Ra} / A^{230} \mathrm{Th}=0.2$, 也就是说, 底 部沉积物再悬浮解吸 $20 \%$ 的镭需要 500 年 ${ }^{[6]}$. 因此, 海底沉积物扩散产生的镭对沿岸地区镭活度的增加贡 献很小.

湖底沉积物 ${ }^{223} \mathrm{Ra} 、{ }^{224} \mathrm{Ra} 、{ }^{226} \mathrm{Ra}$ 和 ${ }^{228} \mathrm{Ra}$ 扩散速率分别是 $0.13 、 4.72 、 0.10$ 和 $0.32 \mathrm{dpm} /\left(\mathrm{m}^{2} \cdot \mathrm{h}\right)$. 大柴旦湖面 
积在 35 45 $\mathrm{km}^{2}$ 之间, 平均水深为 $1 \mathrm{~m}$, 由此得出湖底沉积物扩散的 ${ }^{223} \mathrm{Ra} 、{ }^{224} \mathrm{Ra} 、{ }^{226} \mathrm{Ra}$ 和 ${ }^{228} \mathrm{Ra}$ 约为 $(0.31 \pm$ $0.01) 、(11.33 \pm 0.30) 、(0.24 \pm 0.02)$ 和 $(0.77 \pm 0.30) \mathrm{dpm} /(100 \mathrm{~L})$. 以上分析表明, 底部沉积物扩散的镭与河流 输人的镭相比较是非常少的, 可以忽略, 因为从河流悬浮颗粒物解吸出来的镭比底部沉积物再悬浮解吸的 镭多. 雨水中 ${ }^{226} \mathrm{Ra}$ 和 ${ }^{228} \mathrm{Ra}$ 的活度值很低, 而且大柴旦湖区干旱少雨, 年降水量只有 $900 \mathrm{~mm}$, 所以降水对大 柴旦湖中镭同位素的补给可以忽略.

通过以上分析,我们得出大柴旦湖中镭同位素主要来源于深部地下热水和浅层地下水, 其次河流对大 柴旦湖镭同位素的补给也不能忽略.

3.4.2 大柴旦湖周围水循环过程 雨水中 $\operatorname{Ar}\left({ }^{228} \mathrm{Ra} /{ }^{226} \mathrm{Ra}\right)$ 值非常小 $(0.06)$, 而深部地下热水中 $\operatorname{Ar}\left({ }^{228} \mathrm{Ra} /\right.$ ${ }^{226} \mathrm{Ra}$ ) 值 (2.70) 大于雨水中和表层地下热水中 $\operatorname{Ar}\left({ }^{228} \mathrm{Ra} /{ }^{226} \mathrm{Ra}\right.$ ) 值 (0.66), 这表明表层地下热水受雨水补给. 从深部地下热水到表层地下热水表现出 ${ }^{226} \mathrm{Ra}$ 的累积和 ${ }^{228} \mathrm{Ra}$ 的衰变现象, 由于该区降水量非常少 (年降水量 $60 \sim 80 \mathrm{~mm}$ ), 雨水中 ${ }^{226} \mathrm{Ra}$ 和 ${ }^{228} \mathrm{Ra}$ 的活度值也非常低, 因此降水对表层地下热水的影响也非常小, 从而表明 在地下热水中镭的运移方向是从深部到表层, 这也就表明深部地下热水通过上涌而达到表层. 湖水中 $\operatorname{Ar}\left({ }^{228} \mathrm{Ra} /{ }^{226} \mathrm{Ra}\right)$ 值变化范围在 $1.80 \sim 3.76$ 之间, 平均值为 $2.59(n=32)$, 湖水中的 $\operatorname{Ar}\left({ }^{228} \mathrm{Ra} /{ }^{226} \mathrm{Ra}\right)$ 值与深部 地下热水中的 $\operatorname{Ar}\left({ }^{228} \mathrm{Ra} /{ }^{226} \mathrm{Ra}\right.$ ) 值 (2.70) 非常相似, 而表层地下热水中 $\operatorname{Ar}\left({ }^{228} \mathrm{Ra} /{ }^{226} \mathrm{Ra}\right)$ 值 $(0.66)$ 相差较大, 这表明上涌的地下热水并没有直接补给到盐湖中, 而是经过出山之后全部转化成地下水输人湖盆. 靠近岸 边的湖水中 (7L18) 的 $\operatorname{Ar}\left({ }^{228} \mathrm{Ra} /{ }^{226} \mathrm{Ra}\right.$ ) 值 (2.72) 与深部地下热水 $\operatorname{Ar}\left({ }^{228} \mathrm{Ra} /{ }^{226} \mathrm{Ra}\right.$ ) 较相似 (图 7), 而且在采样 期间, 我们观察到在大柴旦湖中分布有泉眼, 这表明湖水直接受深部地下热水补给非常明显.

浅层地下水中 $\operatorname{Ar}\left({ }^{228} \mathrm{Ra} /{ }^{226} \mathrm{Ra}\right.$ ) 值 (2.43) 介于深部地下热水 $\operatorname{Ar}\left({ }^{228} \mathrm{Ra} /{ }^{226} \mathrm{Ra}\right.$ ) 值 (2.70) 和雨水 $\operatorname{Ar}\left({ }^{228} \mathrm{Ra} /\right.$ ${ }^{226} \mathrm{Ra}$ ) 值 (0.06) 之间, 表明浅层地下水受降水和深部地下热水补给. 河水 $7 \mathrm{R} 7$ 的 $\operatorname{Ar}\left({ }^{228} \mathrm{Ra} /{ }^{226} \mathrm{Ra}\right.$ ) 值介于大头 羊河水 (7R1) 的 $\operatorname{Ar}\left({ }^{228} \mathrm{Ra} /{ }^{226} \mathrm{Ra}\right.$ ) 值与八里沟渠水 (7R2) 的 $\operatorname{Ar}\left({ }^{228} \mathrm{Ra} /{ }^{226} \mathrm{Ra}\right.$ ) 值之间, 表明下游河水是大头羊 河水与八里沟渠水的混合物.

大柴旦湖中 $\operatorname{Ar}\left({ }^{228} \mathrm{Ra} /{ }^{226} \mathrm{Ra}\right)$ 值与深部地下热水中 $\operatorname{Ar}\left({ }^{228} \mathrm{Ra} /{ }^{226} \mathrm{Ra}\right)$ 值和浅层地下水中 $\operatorname{Ar}\left({ }^{228} \mathrm{Ra} /{ }^{226} \mathrm{Ra}\right)$ 值较接近, 明显小于河水 $\operatorname{Ar}\left({ }^{228} \mathrm{Ra} /{ }^{226} \mathrm{Ra}\right)$ 值. 这表明一方面可能是由于河流悬浮颗粒物解吸的原因, 另一方 面可能是湖水受河流补给. 由以上分析可以得出研究区水循环过程是: 雨和冰雪融水下渗补给深部和浅层 地下水以及地表径流; 深部地下热水一部分上涌至表层, 经过出山口之后全部转化为浅层地下水,一部分通 过深大断裂汇集到大柴旦湖; 浅层地下水直接汇集到湖盆; 地表径流一方面下渗后补给浅层地下水,一方面 通过地表径流汇人到湖盆.

\section{4 结论}

1) 3 月份, 从岸边向湖中心, 大柴旦湖湖水的盐度呈现出升高趋势, 随着盐度的增加湖水中 ${ }^{223} \mathrm{Ra}$ 、 ${ }^{224} \mathrm{Ra} 、{ }^{226} \mathrm{Ra}$ 和 ${ }^{228} \mathrm{Ra}$ 活度表现出保守性的降低. 在沿岸近河口区, Ra 活度都非常高, 而盐度相对较低. 7 月 份 ${ }^{223} \mathrm{Ra} 、{ }^{224} \mathrm{Ra} 、{ }^{226} \mathrm{Ra}$ 和 ${ }^{228} \mathrm{Ra}$ 活度先随着盐度的增加而升高, 当盐度大于 $168.99 \%$ 时, 则随着盐度的增加而降 低. 可能是在盐度低时地下水和河水输人的颗粒物中的镭发生解吸, 而盐度较高时, 蒸发强烈, 水体中的物 质结晶,镭与 $\mathrm{Ca} 、 \mathrm{Ba}$ 元素共沉淀.

2) 深部地下热水 ${ }^{223} \mathrm{Ra} 、{ }^{224} \mathrm{Ra}$ 和 ${ }^{228} \mathrm{Ra}$ 的活度值比表层地下热水 ${ }^{223} \mathrm{Ra} 、{ }^{224} \mathrm{Ra}$ 和 ${ }^{228} \mathrm{Ra}$ 的活度值要高 $3 \sim 4$ 倍, 而 ${ }^{226} \mathrm{Ra}$ 正好相反, 表层地下热水中 ${ }^{226} \mathrm{Ra}$ 的活度值比深部地下热水中 ${ }^{226} \mathrm{Ra}$ 的活度值高, ${ }^{226} \mathrm{Ra}$ 在表层具有 明显的积累现象. 这是由于短半衰期 ${ }^{223} \mathrm{Ra} 、{ }^{224} \mathrm{Ra}$ 和 ${ }^{228} \mathrm{Ra}$ 发生衰减, 而长半衰期 ${ }^{226} \mathrm{Ra}$ 得到积累的原因, 从而 表明镭的运移方向是从深部涌到表层.

3) 河口水体中 ${ }^{223} \mathrm{Ra} 、{ }^{224} \mathrm{Ra}$ 和 ${ }^{228} \mathrm{Ra}$ 的活度值小于发源地水体中 ${ }^{223} \mathrm{Ra} 、{ }^{224} \mathrm{Ra}$ 和 ${ }^{228} \mathrm{Ra}$ 的活度值, 而 ${ }^{226} \mathrm{Ra}$ 活 度值比恒定, 这可能是由于水体滞留时间的不同, ${ }^{223} \mathrm{Ra} 、{ }^{224} \mathrm{Ra}$ 和 ${ }^{228} \mathrm{Ra}$ 的半衰期比较短, 随着滞留时间的增加 而衰变的原因.

$4{ }^{226} \mathrm{Ra}$ 和 ${ }^{228} \mathrm{Ra}$ 的最大解吸活度值都发生在盐度为 $125.76 \%$ 时, ${ }^{226} \mathrm{Ra}$ 和 ${ }^{228} \mathrm{Ra}$ 具有相似的解吸模式. 河 流悬浮颗粒物中 ${ }^{224} \mathrm{Ra}$ 的解吸活度相对 ${ }^{226} \mathrm{Ra}$ 和 ${ }^{228} \mathrm{Ra}$ 的解吸活度较高, 这可能与 ${ }^{224} \mathrm{Ra}$ 再生速率快有关. 扩散 的镭同位素活度值非常小, 比误差值还要小, 所以几乎可以忽略. 
5) 大柴旦湖中镭同位素主要来源于深部地下热水、浅层地下水和河流. 大柴旦周围水体水循环过程是 雨和冰雪融水下渗补给深部和浅层地下水以及地表径流; 深部地下热水一部分上涌至表层, 经过出山口之 后全部转化为浅层地下水,一部分通过深大断裂汇集到大柴旦湖; 浅层地下水直接汇集到湖盆; 地表径流在 山区下渗后补给浅层地下水,在丰水期汇人到湖盆.

\section{5 附录}

附表 I 见电子版( DOI: 10.18307/2021.0227).

\section{6 参考文献}

[ 1 ] Chen LZ, Ma T, Ma J et al. Identification of material source for the salt lakes in the Qaidam Basin. Hydrogeology and Engineering Geology, 2015, 42(4) : 101-107. [ 陈柳竹, 马腾, 马杰等. 柴达木盆地盐湖物质来源识别. 水文地质工程 地质, 2015, 42(4): 101-107.]

[ 2 ] Rama MWS. Mechanism of transport of U-Th series radioisotopes from solids into ground water. Geochimica et Cosmochimica Acta, 1984, 48(2) : 395-399. DOI: 10.1016/0016-7037(84)90261-8.

[ 3 ] Dulaiova H, Burnett WC. Evaluation of the Flushing rates of Apalachicola Bay, Florida via natural geochemical tracers. Marine Chemistry, 2008, 109(3/4) : 395-408. DOI: 10.1016/j.marchem.2007.09.001.

[ 4 ] Peterson RN, Burnett WC, Taniguchi M et al. Determination of transport rates in the Yellow River-Bohai Sea mixing zone via natural geochemical tracers. Continental Shelf Research, 2008, 28 (19) : 2700-2707. DOI: 10. 1016/j. csr. 2008. 09.002 .

[ 5 ] Burnett WC, Peterson R, Moore WS et al. Radon and Radium isotopes as tracers of submarine groundwater discharge-Results from the Ubatuba, Brazil SGD assessment intercomparison. Estuarine, Coastal and Shelf Science, 2008, 76(3) : 501511. DOI: $10.1016 /$ j.ecss.2007.07.027.

[ 6 ] Moore WS. Large groundwater inputs to coastal waters revealed by ${ }^{226}$ Ra enrichments. Nature, 1996, 380 (6575): 612 614. DOI: $10.1038 / 380612 \mathrm{a} 0$.

[ 7 ] Moore WS, Sarmiento JL, Key RM. Submarine groundwater discharge revealed by ${ }^{228}$ Ra distribution in the upper Atlantic Ocean. Nature Geoscience, 2008, 1(5) : 309-311. DOI: 10.1038/ngeo183.

[ 8 ] Webster IT, Hancock GJ, Murray AS. Modelling the effect of salinity on Radium desorption from sediments. Geochimica et Cosmochimica Acta, 1995, 59(12) : 2469-2476. DOI: 10.1016/0016-7037(95)00141-7.

[ 9 ] Moore WS. Determining coastal mixing rates using Radium isotopes. Continental Shelf Research, 2000, 20(15) : 19932007. DOI: $10.1016 / \mathrm{s} 0278-4343$ ( 00$) 00054-6$.

[10] Moore WS. Sources and fluxes of submarine groundwater discharge delineated by Radium isotopes. Biogeochemistry, 2003, 66 $(1 / 2)$ : 75-93. DOI: 10.1023/b: biog.0000006065.77764.a0.

[11] Krest JM, Moore WS. ${ }^{226}$ Ra and ${ }^{228}$ Ra in the mixing zones of the Mississippi and Atchafalaya Rivers: indicators of groundwater input. Marine Chemistry, 1999, 64(3): 129-152.

[12] Zhang J, Liu SM, Ren JL et al. Nutrient gradients from the eutrophic Changjiang (Yangtze River) Estuary to the oligotrophic Kuroshio waters and re-evaluation of budgets for the East China Sea Shelf. Progress in Oceanography, 2007, 74(4) : 449-478. DOI: 10.1016/j.pocean.2007.04.019.

[13] Kong FC, Sha ZJ, Du JZ et al. Analysis of the distribution characteristics of ${ }^{226} \mathrm{Ra}$ and ${ }^{228} \mathrm{Ra}$ and their sources in the western part of Qinghai Lake. Chinese Journal of Oceanology and Limnology, 2015, 33(6) : 1402-1412.

[14] Kong FC, Sha ZJ, Luo X et al. Evaluation of lacustrine groundwater discharge and associated nutrients, trace elements and DIC loadings into Qinghai Lake in Qinghai-Tibetan Plateau, using Radium isotopes and hydrological methods. Chemical Geology, 2019, 510: 31-46. DOI: 10.1016/j.chemgeo.2019.01.020.

[15] Luo X, Jiao JJ, Wang XS et al. Groundwater discharge and hydrologic partition of the lakes in desert environment: Insights from stable ${ }^{18} \mathrm{O} /{ }^{2} \mathrm{H}$ and Radium isotopes. Journal of Hydrology, 2017, 546: 189-203. DOI: 10. 1016/j. jhydrol.2017. 01.017.

[16] Breier JA, Edmonds HN. High ${ }^{226}$ Ra and ${ }^{228}$ Ra activities in Nueces Bay, Texas indicate large submarine saline discharges. Marine Chemistry, 2007, 103(1/2) : 131-145. DOI: 10.1016/j.marchem.2006.06.015.

[17] Kim G, Ryu JW, Yang HS et al. Submarine groundwater discharge (SGD) into the Yellow Sea revealed by ${ }^{228}$ Ra and 
${ }^{226}$ Ra isotopes: Implications for global silicate fluxes. Earth and Planetary Science Letters, 2005, 237 (1/2) : 156-166.

[18] Zhao D, Wang GC, Liao F et al. Groundwater-surface water interactions derived by hydrochemical and isotopic ( ${ }^{222} \mathrm{Rn}$, deuterium, oxygen-18) tracers in the Nomhon area, Qaidam Basin, NW China. Journal of Hydrology, 2018, 565: 650-661.

[19] Yang Q. Geological boron deposits of Da qaidam and Xiao qaidam in Qaidam basin, Qinghai Province. Qinghai Geology, 1983，(3) : 38-63. [杨谦. 青海省柴达木盆地大、小柴旦盐湖嗍矿床地质概况. 青海地质，1983，(3) : 38-63.]

[20] Li JY. Distributive regularity of boron and lithium in Da Qaidam salt lake. Journal of Salt Lake Research, 1994, 2(2) : 1824. [李家棪. 大柴旦盐湖硼、锂分布规律 (续). 盐湖研究, 1994, 2(2): 18-24.]

[21] Wang SM, Dou HS eds. The chronicles of Chinese lakes. Beijing: Science Press, 1998. [王苏民, 窦鸿身. 中国湖泊志. 北京: 科学出版社, 1998.]

[22] Zhang Y. Regional hydrogeological survey report-Da qaidam. Qinghai Geological Bureau, 1983. [张勇. 区域水文地质普 查报告大柴旦镇幅. 青海省地质局, 1983.]

[23] Moore WS. Fifteen years experience in measuring ${ }^{224} \mathrm{Ra}$ and ${ }^{223} \mathrm{Ra}$ by delayed-coincidence counting. Marine Chemistry, 2008, 109(3/4) : 188-197. DOI: 10.1016/j.marchem.2007.06.015.

[24] Moore WS. Radium 228 in the south Atlantic bight. Journal of Geophysical Research Atmospheres, 1987, 92 ( C5) : 5177. DOI: $10.1029 /$ jc092ic05p05177.

[25] Moore WS, Arnold R. Measurement of ${ }^{223} \mathrm{Ra}$ and ${ }^{224} \mathrm{Ra}$ in coastal waters using a delayed coincidence counter. Journal of Geophysical Research: Oceans (1978-2012), 1996, 101(1): 1321-1329.

[26] Kiro Y, Weinstein Y, Starinsky A et al. Groundwater ages and reaction rates during seawater circulation in the Dead Sea aquifer. Geochimica et Cosmochimica Acta, 2013, 122: 17-35. DOI: 10.1016/j.gca.2013.08.005.

[27] Levy DM, Moore WS. ${ }^{224}$ Ra in Continental Shelf waters. Earth and Planetary Science Letters, 1985, 73(2/3/4) : 226230. DOI: $10.1016 / 0012-821 \times(85) 90071-8$.

[28 ] Li YH, Mathieu G, Biscaye P et al. The flux of ${ }^{226}$ Ra from estuarine and continental shelf sediments. Earth and Planetary Science Letters, 1977, 37(2) : 237-241. DOI: 10.1016/0012-821x(77) 90168-6.

[29] Astwood HM. The desorption of radium from Amazon sediment. University of South Carolinal, 1991.

[30] Su N, Du JZ, Moore WS et al. An examination of groundwater discharge and the associated nutrient fluxes into the estuaries of eastern Hainan Island, China using ${ }^{226}$ Ra. Science of the Total Environment, 2011, 409(19) : 3909-3918. DOI: 10. 1016/j.scitotenv.2011.06.017.

[31] Kong FC, Sha ZJ, Du JZ et al. Desorption and diffusion characteristics of Radium isotopes from particles in the western part of Lake Qinghai. J Lake Sci, 2016, 28(5) : 1103-1114. DOI: 10.18307/2016.0521. [孔凡翠, 沙占江, 杜金洲等. 青海湖西岸镭同位素的解吸和扩散特征. 湖泊科学, 2016, 28(5): 1103-1114.]

[32] Elsinger RJ, Moore WS. ${ }^{226} \mathrm{Ra}$ and ${ }^{228} \mathrm{Ra}$ in the mixing zones of the pee dee river-Winyah bay, Yangtze River and Delaware bay estuaries. Estuarine, Coastal and Shelf Science, 1984, 18 (6) : 601-613. DOI: 10.1016/0272-7714 (84) 90033-7.

[33] Cable JE, Smith CG, Blanford WJ. Measurements of dispersivity and retardation factors in marine sediments using tritiated calcium chloride solution and Radium-226. Radioprotection, 2009, 44(5) : 185-190.

[34] Beck AJ, Rapaglia JP, Cochran JK et al. Radium mass-balance in Jamaica Bay, NY: Evidence for a substantial flux of submarine groundwater. Marine Chemistry, 2007, 106(3/4) : 419-441. DOI: 10.1016/j.marchem.2007.03.008.

[35] Garcia-Solsona E, Masqué P, Garcia-Orellana J et al. Estimating submarine groundwater discharge around Isola La Cura, northern Venice Lagoon (Italy), by using the Radium quartet. Marine Chemistry, 2008, 109(3/4) : 292-306. DOI: 10. 1016/j.marchem.2008.02.007.

[36] Guo ZR, Huang L, Yuan XJ et al. Estimating submarine groungwater discharge to the Jiulong River estuary using Ra isotopes. Advavces in Water Science, 2011, 22(1): 118-125. [郭占荣, 黄磊, 袁晓婕等. 用镭同位素评价九龙江河口区 的地下水输人. 水科学进展, $2011,22(1): 118-125$. ]

[37] Xue JJ. Characteristics of river silt in the Qaidam basin, China. Arid Zone Research, 2001, 18(4) : 44-46. DOI: 10. 13866/j.azr.2001.04.011. [薛建军. 柴达木盆地河流泥沙特征. 干旱区研究, 2001, 18(4) : 44-46.] 
附表 I 样品镭同位素活度值和其他参数”

Attached Tab. I The Radium isotopes activity and other parameter of samples

\begin{tabular}{|c|c|c|c|c|c|c|c|c|}
\hline $\begin{array}{l}\text { 样品 } \\
\text { 编号 }\end{array}$ & $\begin{array}{c}\text { 纬度/ } \\
\left({ }^{\circ}\right)\end{array}$ & $\begin{array}{c}\text { 经度/ } \\
\left({ }^{\circ}\right)\end{array}$ & $\begin{array}{c}\text { 盐度/ } \\
\% o\end{array}$ & $\begin{array}{c}\text { 离岸距离/ } \\
\mathrm{km}\end{array}$ & $\begin{array}{c}{ }^{224} \mathrm{Ra} / \\
(\mathrm{dpm} /(100 \mathrm{~L}))\end{array}$ & $\begin{array}{c}{ }^{223} \mathrm{Ra} / \\
(\mathrm{dpm} /(100 \mathrm{~L}))\end{array}$ & $\begin{array}{c}{ }^{226} \mathrm{Ra} / \\
(\mathrm{dpm} /(100 \mathrm{~L}))\end{array}$ & $\begin{array}{c}{ }^{228} \mathrm{Ra} / \\
(\mathrm{dpm} /(100 \mathrm{~L}))\end{array}$ \\
\hline $3 \mathrm{~L} 1$ & 37.85 & 95.25 & 233.00 & 1.55 & $119.57 \pm 5.98$ & $9.53 \pm 0.67$ & $26.59 \pm 0.05$ & $67.26 \pm 2.79$ \\
\hline $3 \mathrm{~L} 2$ & 37.85 & 95.25 & 240.41 & 1.53 & $84.12 \pm 4.21$ & $5.76 \pm 0.4$ & $19.01 \pm 0.07$ & $48.53 \pm 2.03$ \\
\hline $3 \mathrm{~L} 3$ & 37.85 & 95.25 & 240.41 & 1.52 & $54.99 \pm 2.75$ & $1.91 \pm 0.13$ & $20.13 \pm 0.06$ & $67.87 \pm 1.93$ \\
\hline 3L3-1 & 37.85 & 95.25 & 240.41 & 1.52 & - & - & $3.29 \pm 0.05$ & $5.61 \pm 0.64$ \\
\hline 3L4 & 37.86 & 95.26 & 234.75 & 1.40 & $25.04 \pm 1.25$ & $0.42 \pm 0.03$ & $19.85 \pm 0.03$ & $74.04 \pm 2.74$ \\
\hline $3 \mathrm{~L} 5$ & 37.86 & 95.26 & 240.26 & 1.38 & $126.16 \pm 6.31$ & $7.55 \pm 0.53$ & $37.59 \pm 0.05$ & $78.77 \pm 3.02$ \\
\hline 3L6 & 37.86 & 95.26 & 239.58 & 1.21 & $27.82 \pm 1.39$ & $3.52 \pm 0.25$ & $19.19 \pm 0.02$ & $44.5 \pm 0.99$ \\
\hline $3 \mathrm{~L} 7$ & 37.86 & 95.26 & 239.58 & 1.26 & $100.57 \pm 5.03$ & $1.80 \pm 0.13$ & $23.08 \pm 0.05$ & $54.72 \pm 2.80$ \\
\hline $3 \mathrm{~L} 8$ & 37.86 & 95.26 & 235.59 & 1.00 & $113.73 \pm 5.69$ & $7.58 \pm 0.53$ & $27.59 \pm 0.05$ & $72.36 \pm 2.84$ \\
\hline $3 \mathrm{~L} 9$ & 37.86 & 95.26 & 217.61 & 0.48 & $37.69 \pm 1.88$ & $4.61 \pm 0.32$ & $34.76 \pm 0.05$ & $83.84 \pm 1.91$ \\
\hline $3 \mathrm{~L} 10$ & 37.85 & 95.26 & 41.83 & 0.01 & $581.00 \pm 29.05$ & $8.48 \pm 0.59$ & $79.56 \pm 0.04$ & $233.36 \pm 1.78$ \\
\hline 3L11 & 37.87 & 95.26 & 168.99 & 0.06 & $544.87 \pm 27.24$ & $7.90 \pm 0.55$ & $85.97 \pm 0.05$ & $217.04 \pm 2.18$ \\
\hline 3L12 & 37.87 & 95.26 & 187.97 & 0.12 & $350.21 \pm 17.51$ & $12.95 \pm 0.91$ & $50.7 \pm 0.05$ & $127.61 \pm 2.24$ \\
\hline $7 \mathrm{~L} 1$ & 37.85 & 95.28 & 44.60 & 0.60 & $213.20 \pm 10.66$ & $24.32 \pm 1.70$ & $71.01 \pm 0.05$ & $233.13 \pm 0.61$ \\
\hline 7L2 & 37.85 & 95.28 & 44.20 & 0.66 & $172.65 \pm 8.63$ & $14.02 \pm 0.98$ & - & - \\
\hline 7L3 & 37.85 & 95.28 & 43.80 & 0.75 & $158.42 \pm 7.92$ & $9.83 \pm 0.69$ & $91.65 \pm 0.04$ & $206.95 \pm 0.61$ \\
\hline 7L4 & 37.85 & 95.28 & 43.40 & 0.82 & $162.80 \pm 8.14$ & $22.60 \pm 1.58$ & $94.37 \pm 0.05$ & $215.77 \pm 0.61$ \\
\hline 7L5 & 37.85 & 95.28 & 37.40 & 0.86 & $229.35 \pm 11.47$ & $19.28 \pm 1.35$ & $104.80 \pm 0.05$ & $216.86 \pm 0.61$ \\
\hline 7L6 & 37.85 & 95.28 & 42.80 & 0.92 & $234.17 \pm 11.71$ & $11.04 \pm 0.77$ & $101.57 \pm 0.04$ & $214.52 \pm 0.61$ \\
\hline 7L7 & 37.85 & 95.28 & 42.10 & 1.01 & $144.16 \pm 7.21$ & $14.46 \pm 1.01$ & $140.54 \pm 0.05$ & $258.23 \pm 0.61$ \\
\hline 7L8 & 37.85 & 95.28 & 41.30 & 1.11 & $165.56 \pm 8.28$ & $27.76 \pm 1.94$ & $98.32 \pm 0.05$ & $211.37 \pm 0.61$ \\
\hline 7L9 & 37.85 & 95.28 & 41.00 & 1.21 & $166.74 \pm 8.34$ & $17.55 \pm 1.23$ & $114.63 \pm 0.05$ & $227.59 \pm 0.61$ \\
\hline 7L10 & 37.85 & 95.27 & 3.00 & 1.38 & $10.66 \pm 0.53$ & $3.44 \pm 0.24$ & $38.48 \pm 0.04$ & $144.59 \pm 0.59$ \\
\hline 7L11 & 37.85 & 95.28 & 1.90 & 0.90 & $81.81 \pm 4.09$ & $4.70 \pm 0.33$ & $27.17 \pm 0.04$ & $81.87 \pm 0.58$ \\
\hline 7L12 & 37.85 & 95.27 & 24.60 & 1.37 & $76.03 \pm 3.80$ & $16.11 \pm 1.13$ & $74.37 \pm 0.04$ & $146.76 \pm 0.57$ \\
\hline 7L13 & 37.85 & 95.27 & 240.00 & 1.45 & $47.63 \pm 2.38$ & $9.81 \pm 0.69$ & $5.02 \pm 0.02$ & $16.84 \pm 0.08$ \\
\hline 7L14 & 37.85 & 95.27 & 52.10 & 1.48 & $331.24 \pm 16.56$ & $13.07 \pm 0.91$ & $116.77 \pm 0.05$ & $248.18 \pm 0.61$ \\
\hline 7L15 & 37.85 & 95.27 & 11.40 & 2.00 & $35.30 \pm 1.76$ & $4.05 \pm 0.28$ & $64.92 \pm 0.04$ & $116.67 \pm 0.57$ \\
\hline 7L16 & 37.84 & 95.26 & 4.30 & 2.53 & $63.41 \pm 3.17$ & $5.93 \pm 0.42$ & $48.09 \pm 0.06$ & $88.48 \pm 0.78$ \\
\hline 7L17 & 37.85 & 95.27 & 5.20 & 1.65 & $79.05 \pm 3.95$ & $3.83 \pm 0.27$ & $52.46 \pm 0.04$ & $111.53 \pm 0.56$ \\
\hline 7L18 & 37.87 & 95.26 & 219.53 & 0.10 & $305.61 \pm 15.28$ & $13.95 \pm 0.98$ & $37.74 \pm 0.04$ & $102.65 \pm 0.52$ \\
\hline 7L19 & 37.79 & 95.24 & 236.16 & 0.10 & $103.01 \pm 5.15$ & $1.92 \pm 0.13$ & $25.53 \pm 0.04$ & $89.23 \pm 0.56$ \\
\hline 7L20 & 37.79 & 95.24 & - & 0.17 & $124.27 \pm 6.21$ & $5.95 \pm 0.42$ & $33.62 \pm 0.04$ & $109.75 \pm 0.56$ \\
\hline 7L21 & 37.79 & 95.24 & 235.66 & 0.27 & $98.73 \pm 4.94$ & $3.61 \pm 0.25$ & $27.47 \pm 0.03$ & $89.72 \pm 0.56$ \\
\hline $3 \mathrm{WS} 1$ & 37.93 & 95.38 & 0.63 & 11.86 & $31.34 \pm 1.57$ & - & $95.16 \pm 0.06$ & $54.22 \pm 2.39$ \\
\hline $7 \mathrm{WS} 1$ & 37.93 & 95.38 & 0.90 & 12.28 & $664.32 \pm 33.22$ & $12.58 \pm 0.88$ & $1190.49 \pm 0.07$ & $889.24 \pm 0.71$ \\
\hline $7 \mathrm{WS} 2$ & 37.93 & 95.38 & 0.90 & 12.25 & $1924.72 \pm 96.24$ & $51.13 \pm 3.58$ & $891.93 \pm 0.06$ & $2404.44 \pm 0.83$ \\
\hline $3 \mathrm{SC} 1$ & 37.86 & 95.4 & 0.21 & 9.35 & $170.02 \pm 8.50$ & $35.79 \pm 2.51$ & $41.44 \pm 0.09$ & $116.36 \pm 3.77$ \\
\hline $3 \mathrm{SC} 2$ & 37.88 & 95.26 & 0.13 & 1.15 & $43.52 \pm 2.18$ & - & $34.74 \pm 0.06$ & $84.64 \pm 2.42$ \\
\hline $3 \mathrm{SC} 3$ & 37.91 & 95.20 & 0.20 & 1.19 & $48.28 \pm 2.41$ & $1.81 \pm 0.13$ & $22.46 \pm 0.04$ & $61.92 \pm 1.88$ \\
\hline 7CS1 & 37.79 & 95.47 & 0.24 & 16.47 & $26.00 \pm 1.30$ & $3.79 \pm 0.27$ & $20.50 \pm 0.03$ & $37.33 \pm 0.11$ \\
\hline 7CS2 & 37.79 & 95.47 & 0.50 & - & - & - & - & - \\
\hline $3 \mathrm{R} 1$ & 37.86 & 95.34 & 0 & 0.11 & $218.03 \pm 10.9$ & $12.09 \pm 0.85$ & $89.63 \pm 0.05$ & $209.59 \pm 0.70$ \\
\hline $3 \mathrm{R} 2$ & 37.87 & 95.26 & 0.24 & 4.64 & $111.34 \pm 5.57$ & $3.64 \pm 0.26$ & $25 \pm 0.03$ & $218.81 \pm 0.69$ \\
\hline
\end{tabular}


续附表 I

\begin{tabular}{ccccccccc}
\hline $\begin{array}{c}\text { 样品 } \\
\text { 编号 }\end{array}$ & $\begin{array}{c}\text { 纬度/ } \\
\left({ }^{\circ}\right)\end{array}$ & $\begin{array}{c}\text { 经度/ } \\
\left({ }^{\circ}\right)\end{array}$ & $\begin{array}{c}\text { 盐度/ } \\
\% 0\end{array}$ & $\begin{array}{c}\text { 离岸距离/ } \\
\mathrm{km}\end{array}$ & $\begin{array}{c}{ }^{224} \mathrm{Ra} / \\
(\mathrm{dpm} /(100 \mathrm{~L}))\end{array}$ & $\begin{array}{c}{ }^{223} \mathrm{Ra} / \\
(\mathrm{dpm} /(100 \mathrm{~L}))\end{array}$ & $\begin{array}{c}{ }^{226} \mathrm{Ra} / \\
(\mathrm{dpm} /(100 \mathrm{~L}))\end{array}$ & $\begin{array}{c}{ }^{228} \mathrm{Ra} / \\
(\mathrm{dpm} /(100 \mathrm{~L}))\end{array}$ \\
\hline 7R1 & 37.79 & 95.46 & 0.50 & 15.53 & $76.26 \pm 3.81$ & $1.56 \pm 0.11$ & $16.83 \pm 0.02$ & $99.54 \pm 0.32$ \\
$7 \mathrm{R} 2$ & 37.86 & 95.41 & 0.30 & 10.06 & $91.17 \pm 4.56$ & $1.34 \pm 0.09$ & $7.27 \pm 0.05$ & $101.24 \pm 0.70$ \\
7R3 & 37.86 & 95.40 & 0.30 & 9.77 & $90.65 \pm 4.53$ & $0.86 \pm 0.06$ & $7.83 \pm 0.05$ & $100.49 \pm 0.68$ \\
7R4 & 37.73 & 95.31 & 0.40 & 8.49 & $10.75 \pm 0.54$ & $0.60 \pm 0.04$ & $4.45 \pm 0.04$ & $30.26 \pm 0.09$ \\
7R5 & 37.87 & 95.26 & 0.30 & 0.10 & $20.39 \pm 1.02$ & $0.30 \pm 0.02$ & $7.67 \pm 0.04$ & $34.94 \pm 0.08$ \\
7R6 & 37.87 & 95.26 & 0.40 & 0.01 & $21.13 \pm 1.06$ & - & $8.16 \pm 0.04$ & $30.88 \pm 0.08$ \\
7R7 & 37.84 & 95.34 & 0.40 & 2.95 & $119.08 \pm 5.95$ & $1.40 \pm 0.10$ & $14.09 \pm 0.04$ & $179.7 \pm 0.58$ \\
7R8 & 37.84 & 95.29 & 0.50 & 0.02 & $17.45 \pm 0.87$ & $1.13 \pm 0.08$ & $11.58 \pm 0.02$ & $58.73 \pm 0.27$ \\
Rain & - & - & - & - & - & - & $12.72 \pm 0.25$ & $0.82 \pm 0.01$ \\
\hline
\end{tabular}

$* 3 \mathrm{~L}$ 为 3 月份湖水样品, $7 \mathrm{~L}$ 为 7 月湖水样品, $3 \mathrm{WS}$ 为 3 月温泉水样品, $7 \mathrm{WS}$ 为 7 月温泉水样品, $3 \mathrm{CS}$ 为 3 月冷泉水样品, $7 \mathrm{CS}$ 为 7 月冷泉水样品, $3 \mathrm{R}$ 为 3 月河流样品. $7 \mathrm{R}$ 为 7 月河流样品, Rain 是雨水样品, 一代表数据未检测到. 